\title{
An ASSESSMENT OF THE OPTIMAL TIMING AND SIZE OF InVESTMENTS IN CONCENTRATED SOLAR POWER
}

\author{
Emanuele Massetti ${ }^{1}$ and Elena Claire Ricci ${ }^{2}$
}

\begin{abstract}
$\underline{\text { Abstract }}$
We extend the WITCH model to consider the possibility to produce and trade electricity generated by large scale concentrated solar power plants (CSP) in highly productive areas that are connected to demand centres through High Voltage Direct Current cables. We test the attractiveness of the CSP option by imposing a global cap on Greenhouse gases concentration equal to $535 \mathrm{ppm} \mathrm{CO}_{2}$-eq in 2100 , with and without constraints to the expansion of nuclear power and IGCC coal with carbon capture and storage (CCS). We find that it becomes optimal to produce with CSP from 2040 and to trade CSP electricity across the Mediterranean from 2050. Therefore projects like DESERTEC seem to be premature. After 2050, CSP electricity shares become significant. CSP has a high stabilization cost option value: depending on the constraints, it ranges between $2.1 \%$ to $4.1 \%$ of discounted GDP in the Middle East and North Africa (MENA), between 1.1. and 3.4 in China, between $0.2 \%$ and $1.2 \%$ in the USA, between 0.1 and $1.3 \%$ in Eastern Europe and between 0.1 and $0.4 \%$ in Western Europe. A moderate level of subsidy to invest more and earlier in CSP might increase welfare. However, large-scale deployment should occur after 2040. We also show that MENA countries have the incentive to form a cartel to sell electricity to Europe at a price higher than the marginal cost. This suggests that a hypothetical Mediterranean market for electricity should be carefully regulated.
\end{abstract}

Keywords: climate policy, integrated assessment, renewable energy, concentrated solar power, supergrids, electricity trade

JEL Classification: Q2, Q43, Q54

${ }^{1}$ Yale University, Fondazione Eni Enrico Mattei and CMCC

${ }^{2}$ University of Milan, Fondazione Eni Enrico Mattei and CMCC

Corresponding author: Emanuele Massetti, emanuele.massetti@yale.edu. Yale School of Forestry\& Environmental Studies, 195 Prospect Street, New Haven, CT 06511, USA, +1 2034365783.

This paper is part of the research work being carried out by the Sustainable Development Programme at the Fondazione Eni Enrico Mattei and by the Climate Impacts and Policy Division at CMCC. The research leading to these results has received funding from European Community's Seventh Framework Programme (FP7/2007-2013) under grant agreement n 266992 - Global-IQ "Impacts Quantification of global changes". Emanuele Massetti gratefully acknowledges funding from the Marie Curie IOF CliEMA "Climate change impacts - Economic modeling and analysis".

"NOTICE: THIS IS THE AUTHOR'S VERSION OF A WORK THAT WAS ACCEPTED FOR PUBLICATION IN ENERGY ECONOMICS. CHANGES RESULTING FROM THE PUBLISHING PROCESS, SUCH AS PEER REVIEW, EDITING, CORRECTIONS, STRUCTURAL FORMATTING, AND OTHER QUALITY CONTROL MECHANISMS MAY NOT BE REFLECTED IN THIS DOCUMENT. CHANGES MAY HAVE BEEN MADE TO THIS WORK SINCE IT WAS SUBMITTED FOR PUBLICATION. A DEFINITIVE VERSION WAS SUBSEQUENTLY PUBLISHED IN ENERGY ECONOMICS, FORTHCOMING."

THIS VERSION SUPERSEDES THE WORKING PAPER: MASSETTI, E. AND E.C. RICCI (2011). "SUPER-GRIDS AND CONCENTRATED SOLAR POWER: A SCENARIO ANALYSIS WITH THE WITCH MODEL.” FEEM NOTA DI LAVORO NO. 047.2011. 


\section{Introduction}

This study assesses the role of concentrated solar power (CSP) as a technology option in long-term scenarios of climate change mitigation policy. The paper examines the economic attractiveness of CSP, the optimal timing and size of investments, how CSP affects the optimal mix of power sector technologies, and it carefully discusses the timing, size and institutional requirements of an electricity trade across the Mediterranean.

CSP is an attractive option in climate change mitigation scenarios because electricity is generated by means of solar radiation, an almost infinite energy source, with no direct emissions of $\mathrm{CO}_{2}$ nor of other pollutants. Compared to other zero-carbon renewable resources, it has an advantage as in CSP plants heat can be stored (up to fifteen hours) in order to generate a constant flow of electricity.

However, CSP needs direct solar beams (direct normal irradiance, DNI ${ }^{1}$ ) while photovoltaic also relies on horizontal irradiation. Therefore, one of the most critical issues for CSP is the location of the power plants. The best sites for this power generating technology are found in dry regions near the equator - e.g. the Sahara Desert - which are typically far away from where electricity is consumed. ${ }^{2}$ A large expansion of CSP thus requires the deployment of high-efficiency and high-capacity transmission cables that can cover long distances with minimal losses. High-voltage direct current (HVDC) cables - sometimes referred to as super-grids (SG) - have these characteristics and can be used to transmit electricity at very long distances, connecting supply of CSP in remote areas of the world to demand in dense urban and industrialized areas. The future of CSP and the development of future power grids are therefore strictly intertwined.

The possibility of using CSP to generate electricity with no $\mathrm{CO}_{2}$ emissions and very low intermittency is clearly very attractive and explains the growing interest that surrounds this technology option.

Researchers, government agencies and environmental activists are supporting very ambitious deployment plans for CSP on both the sides of the Atlantic. For example, the Desertec project foresees a large number of CSP plants in Northern Africa connected to the European power network by means of a SG that stretches across the Mediterranean supplying up to $15 \%$ of the electricity consumed in Europe (Trieb and Müller-Steinhagen, 2007). The Mediterranean Solar Plan, sponsored by the Union for the Mediterranean, has the aim to set up a trade between the European Union (EU) and developing countries belonging to the newly established international organization by 2020 , with electricity generated from $10-12 \mathrm{GW}$ of installed capacity. ${ }^{3}$ The U.S. Department of Energy (DOE) has ambitious plans for solar energy and CSP in particular. The objective is to make CSP competitive in the intermediate power market by 2015 . By developing advanced technologies that will reduce system and storage costs, the goal is to make CSP competitive in the base-load power market by 2020 (US DOE, 2008). ${ }^{4}$ Also the International Energy

\footnotetext{
${ }^{1}$ Direct Normal Irradiation (DNI) is the amount of solar radiation received per unit area by a surface that is oriented perpendicular (or normal) to the sun rays. It is measured in $\mathrm{kWh} / \mathrm{m}^{2}$ over a period of time.

${ }^{2}$ A list of cities that are close to areas with high DNI is found in IEA (2011, p. 22).

${ }^{3} \mathrm{http}: / / \mathrm{www}$.ufmsecretariat.org/en/energy/ last accessed on August 162011.

${ }^{4}$ Department of Energy, Solar Technologies Program website, last accessed on August 16 2011: http://www1.eere.energy.gov/solar/csp_program.htm
} 
Agency (IEA) sees a bright future for CSP. In the CSP Technology Roadmap (IEA, 2010b), the IEA depicts a scenario that foresees $148 \mathrm{GW}$ of capacity installed globally by 2020 to supply electricity for intermediate and peak loads. This requires a 200-fold expansion of the global installed capacity, equal to 0.7 GW at beginning of 2009. 2,300 new power plants the same size of the recently built "Nevada Solar One" plant need to start operating in less than ten years. According to the same scenario, in 2020 CSP technologies are expected to become competitive with coal-fired base-load power plants (IEA, 2010b). According to the IEA, Europe will finance the expansion of CSP in Northern Africa because of limited land availability and low DNI. Global installed capacity reaches $337 \mathrm{GW}$ in 2020 and 1,089 GW in 2050, supplying $11 \%$ of global electricity production. The only limit to further expansion is a constraint in supply before 2020 and a limit on exports to areas with high demand and low DNI between 2020 and 2050.

The scenario depicted by the IEA requires a level of effort that goes beyond the present prospects for CSP, as documented by Arvizu et al. (2011), which assesses the literature on CSP for the IPCC Special Report on Renewable Energy (SRREN). With heavy subsidies Spain has pre-registered plants for 2.3 $\mathrm{GW}$; in the USA 4.5 GW are under power purchase agreement contracts to deliver electricity between 2010 and 2015. The global installed capacity of CSP is expected to be equal to $10 \mathrm{GW}$ in 2015 .

There are very few peer-reviewed studies that assess the role of CSP in future energy systems. Krey and Clarke (2011) use a large recent database of scenarios to assess the role of renewable energy in meeting future climate mitigation targets. This is the only study that shows the range of estimates for CSP electricity generation in 2020, 2030 and 2050. The limit of this study is that of reviewing scenarios with very different assumptions on technological availability, timing of climate policy and fossil fuels costs. It is therefore unclear if the range of estimates is driven by different model characteristics or by the assumptions on the scenarios. Moreover, Krey and Clarke (2011) does not present data on international trade of electricity.

To our knowledge, the only analysis of CSP and of SG in a sophisticated economic model is the paper by Bauer et al. (2008). The main focus of the study concerns the political barriers to the electricity trade between Europe and the Middle Eastern and North African region (MENA), with a focus on the impact on macroeconomic activity, sectoral output and trade relations.

Other studies in the literature are mainly policy analysis and scenario analysis (Jacobson and Delucchi, 2010; Patt et al., 2008; Trieb, 2006; Ummel and Wheeler, 2008; Williges et al., 2010).

With this article we contribute to the literature by assessing the incentives to invest in CSP in a systematic way using the integrated assessment model WITCH (World Induced Technical Change Hybrid - Bosetti et al., 2006, 2007a, 2007b, 2009; www.witchmodel.org).

We examine and disentangle the driving forces that create the incentive to invest in CSP and in SG with a regional detail. In particular, we evaluate how the incentive to invest in CSP changes when we limit the expansion of nuclear power and of Integrated Gasification Combined Cycle (IGCC) coal with carbon 
capture and storage (CCS). However, we do not limit our analysis to technological aspects. We examine also economic and geo-political issues.

On the technological side we are interested in examining (i) the optimal timing and size of CSP power generation, (ii) the Europe-MENA trade of CSP electricity, (iii) the impact of CSP on the electricity mix. On the economic and geo-political side we examine (iv) investments and cost dynamics, (v) the option value of CSP, (vi) the feasibility of the foreseen expansion of CSP, (vii) the economic and energy-system implications of forcing earlier investments in CSP and (viii) the plausibility, implications and the regulatory requirements of a non-competitive Europe-MENA electricity market.

In this study we restrict the possibility to invest in CSP to MENA, the USA and China. These regions have sites with high DNI and represent a large share of global energy consumption and global emissions (approximately 60\% of global primary energy supply and of fossil fuel emissions from 2005 to 2050 in our Business-as-Usual scenario). The Eastern and Western European regions (E-EU and W-EU, respectively) can import CSP electricity from the MENA region if a SG is built across the Mediterranean. Future work will include CSP in Australia, Brazil and Indonesia as these are the other world regions with the most potential for CSP production (Trieb, 2009b).

To our knowledge, our analysis is the most comprehensive in the literature. Compared to previous policy scenarios in the non-peer reviewed literature we use a solid energy-economy modelling framework. Contrary to those studies our analysis has a global scope, the mitigation effort is distributed efficiently across countries, between energy efficiency and de-carbonization measures, across technologies and time. With respect to Bauer et al. (2008) we make further considerations on the nature of the electricity trade between the Europe and MENA; we also introduce CSP and SG in the USA and in China, and we study the implications of technological constraints on investments in CSP. Compared to Krey and Clarke (2011) this study assesses in detail the incentives to invest in CSP and provides results on the EuroMENA trade.

The rest of the paper is structured as follows. Section 2 briefly introduces the reader to the WITCH model. Section 3 illustrates the major modelling assumptions. Section 4 provides technical details and information on the calibration of the model. Section 5 illustrates the scenarios and Section 6 presents and discusses the results. Section 7 explores the implications of forcing earlier investments in CSP and Section 8 examines the possibility that MENA acts as a monopolist and sells to Europe electricity at a price higher than its marginal cost. A final Section summarizes the major findings of the paper and illustrates future research work. The Appendix contains the full list of equations and variables; the online Appendix presents the results of the sensitivity analysis.

\section{A brief description of the WITCH model}

WITCH - World Induced Technical Change Hybrid - is a regional integrated assessment model (IAM) structured to provide normative information on the optimal responses of world economies to climate policies (Bosetti et al., 2006, 2007a). 
It is a hybrid model because it combines features of both top-down and bottom-up modelling: the topdown component consists of an inter-temporal optimal growth model in which the energy input of the aggregate production function has been integrated into a bottom-up like description of the energy sector. WITCH's top-down framework guarantees a coherent, fully intertemporal allocation of investments, including those in the energy sector.

World countries are aggregated in twelve regions on the basis of geographic, economic and technological vicinity. The regions interact strategically on global externalities: Greenhouse Gases (GHG), technological spillovers, and a common pool of exhaustible natural resources. ${ }^{5}$

In WITCH emissions arise from fossil fuels used in the energy sector and from land use changes that release carbon sequestered in biomasses and soils. Emissions of $\mathrm{CH}_{4}, \mathrm{~N}_{2} \mathrm{O}, \mathrm{SLF}$ (short-lived fluorinated gases), LLF (long-lived fluorinated), and $\mathrm{SO}_{2}$ aerosols - which have a cooling effect on temperature - are also identified. Since most of these gases arise from agricultural practices, the modelling relies on estimates for reference emissions, and a top-down approach for mitigation supply curves. ${ }^{6}$

A climate module governs the accumulation of emissions in the atmosphere and the temperature response to growing GHG concentrations. WITCH is also equipped with a damage function that provides the feedback on the economy of global warming. However, in this study we exclude the damage function and we take the so-called "cost-minimization" approach: given a target in terms of GHG concentrations in the atmosphere, we produce scenarios that minimize the cost of achieving this target.

Endogenous technological dynamics are a key feature of WITCH. Dedicated R\&D investments increase the knowledge stock that governs energy efficiency. Learning-by-doing curves are used to model cost dynamics for wind and solar power capital costs. Both energy-efficiency R\&D and learning exhibit international spillovers. Two backstop technologies - one in the electricity sector and the other in the non-electricity sector - necessitate dedicated innovation investments to become competitive. The costs of these backstop technologies are modelled through a so-called two-factor learning curve, in which price declines both with investments in dedicated R\&D, and with technology diffusion.

The base year for calibration is 2005; all monetary values are in constant 2005 USD. The WITCH model uses market exchange rates for international income comparisons.

\footnotetext{
${ }^{5}$ The regions are USA, W-EU (Western Europe), E-EU (Eastern Europe), KOSAU (South Korea, South Africa and Australia), CAJANZ (Canada, Japan and New Zealand), TE (Transition Economies), MENA (Middle East and South Africa), SSA (Sub-Saharan Africa), SASIA (South Asia), SEASIA (South-East Asia), CHINA (China, Hong Kong, Taiwan and Macao), LACA (Latin America and the Caribbean).

${ }^{6}$ Reducing emissions from deforestation and degradation (REDD) is estimated to offer sizeable low-cost abatement potential. WITCH includes a baseline projection of land use $\mathrm{CO}_{2}$ emissions, as well as estimates of the global potential and costs for reducing emissions from deforestation, assuming that all tropical forest nations can join an emission trading system and have the capacity to implement REDD programs. However, avoided deforestation is not a source of emission reductions in the version of the model that we used for this study.
} 


\section{Modelling assumptions}

Demand for electricity arises endogenously in each region as the solution of the utility maximization problem in which electric and non-electric energy use provide energy services which are combined with capital and labour to generate the output of the economy. Total electricity demand is an aggregate of electricity generated by various technologies, combined using a constant elasticity of substitution (CES) function. We describe the energy nest in Figure 1 and we list the equations in the Appendix. In our simulations, electricity from CSP will enter various nodes depending on the region, as explained further in Section 4. The mix of different power generation technologies is endogenously determined in each region. With the exception of electricity from CSP, power generation cannot be traded among regions.

Total demand for electricity from CSP in region $n$ at time $t\left(E L_{C S P, T}\right)$ must be equal to domestic production $\left(E L_{C S P}\right)$ plus net imports $\left(E L_{C S P, X}\right)$ :

$$
E L_{C S P, T}(n, t)=E L_{C S P}(n, t)+E L_{C S P, X}(n, t)
$$

with $E L_{C S P, X}(n, t)<0$ in exporting regions. In this paper we focus on three producing countries: the MENA region, the USA and China; therefore we fix $\operatorname{EL}_{C S P}(n, t)=0$ in all other regions. Trade occurs only between MENA and Western and Eastern Europe (W-EU and E-EU), therefore $E L_{C S P, X}(n, t)=0$ for all other regions.

The international price for CSP electricity emerges endogenously as the market clearing price that equates demand and supply in each time period:

$$
\sum_{n} E L_{C S P, X}(n, t)=0 \quad \forall t
$$

The revenue (expenditure) for CSP electricity is added (subtracted) from the regional domestic production $(\mathrm{G} Y)$ :

$Y(n, t)=G Y(n, t)-\sum_{q} p_{q} V_{q}(n, t)-E L_{C S P, X}(n, t) P_{C S P}(t)$

where $G Y$ is gross output, $\sum_{q} p_{q} V_{q}(n, t)$ the sum of expenditures on several inputs, and $P_{C S P}$ the market price for CSP electricity, as detailed in the Appendix.

Investments and Operation and Maintenance costs $(\mathrm{O} \& \mathrm{M})$ for CSP generation $\left(I_{C S P}, O \& M_{C S P}\right)$ and for the SG infrastructure $\left(I_{\text {grid,T }}, O \& M_{\text {grid,T }}\right)$ enter the budget constraint:

$C(n, t)=Y(n, t)-I_{c}(n, t)-\sum_{w} p_{w} Z_{w}(n, t)-I_{C S P}(n, t)-I_{g r i d, T}(n, t)-O \& M_{C S P}(n, t)-O \& M_{g r i d, T}(n, t)$, 
where $Y$ is output of the economy, $I_{c}$ is the investment in the final good sector, $\sum_{w} p_{w} Z_{w}(n, t)$ is the expenditure for investments in the energy sector, in R\&D and other expenses that are detailed in the Appendix.

The amount of CSP electricity $\left(E L_{C S P}\right)$ supplied to the grid of each region $n$ is determined combining in fixed proportions: $(i)$ the generation capacity accumulated in each region $\left(K_{C S P, n}\right)$, measured in power units, corrected through an efficiency coefficient (plant utilization rate) $\mu_{C S P, n}$, that indicates the number of yearly full load hours that a concentrating solar power plant in the specific region may provide; (ii) CSP plants operation and maintenance $\left(O \& M_{C S P, n}\right)$, measured in USD, converted into energy units by $\theta_{\mathrm{CSP}}$; (iii) the capacity of the SG $\left(K_{\text {grid,n }}\right)$ to transmit electricity from remote areas to the local grid, measured in power units, with its efficiency coefficient $\mu_{\text {grid, },}$; and (iv) operation and maintenance for the $\mathrm{SG}\left(O \& M_{\text {grid, } n}\right)$, measured in USD, converted into energy units by $\theta_{\text {grid }}$. Thus the production function of CSP electricity is of the Leontief type:

$E L_{C S P}(n, t)=\min \left\{\mu_{C S P, n} K_{C S P}(n, t) ; \theta_{C S P} O \& M_{C S P}(n, t) ; \mu_{\text {grid }, n} K_{\text {grid }}(n, t) ; \theta_{\text {grid }} O \& M_{\text {grid }}(n, t)\right\}$

If investments in transmission infrastructure - i.e. the $\mathrm{SG}$ - are sufficient to cover the distance between the networks of two regions, the electricity from CSP power plants can also be exported. The production function for exported CSP electricity differs from the production function of domestically consumed CSP electricity only for different grid requirements:

$$
E L_{C S P, X}(n, t)=\min \left\{\mu_{n, C S P} K_{C S P}(n, t) ; \theta_{C S P} O \& M_{C S P}(n, t) ; \mu_{n, X} K_{\text {grid }, X}(n, t) ; \theta_{\text {grid }} O \& M_{\text {grid }, X}(n, t)\right\},
$$

where the index $X$ stands for exports.

Power generation capacity in CSP accumulates as follows:

$$
K_{C S P}(n, t+1)=K_{C S P}(n, t)\left(1-\delta_{C S P}\right)+\frac{I_{C S P}(n, t)}{S C_{C S P}(n, t)}
$$

where $\delta_{C S P}$ represents the CSP capital depreciation rate, and $S C_{C S P}$ the unit investment cost of installing CSP generation capacity.

The grid infrastructure grows following the standard law of motion for capital accumulation in energy technologies in the model. Investments buy grid capacity at the current price $\left(S C_{\text {grid }}\right)$ while the grid depreciates at the rate $\delta_{\text {grid }}$ :

$$
K_{\text {grid }}(n, t+1)=K_{\text {grid }}(n, t)\left(1-\delta_{\text {grid }}\right)+\frac{I_{\text {grid }}(n, t)}{S C_{\text {grid }}(n, t)} .
$$

Total installed SG capacity includes the SG used for domestic consumption and for export:

$$
K_{\text {grid }, T}(n, t)=K_{\text {grid }}(n, t)+K_{\text {grid }, X}(n, t) .
$$


We assume that the operation and the maintenance of the grid are costly and that such expenditures are needed for both the domestic and the international super-grid:

$O \& M_{\text {grid }, T}(n, t)=O \& M_{\text {grid }}(n, t)+O \& M_{\text {grid }, X}(n, t)$.

Investment costs for CSP plants follow a one-factor learning curve depending on cumulative world capacity $(T K)$ in CSP power plants with an additional "saturation" term that increases costs as the regional installed capacity in the current year $\left(I_{C S P} / S C_{C S P}\right)$ increases:

$S C_{C S P}(n, t+1)=S C_{C S P}\left(n, t_{0}\right){\frac{T K(t)}{T K\left(t_{0}\right)}}^{-(\alpha)}\left(1+\left(\frac{\left(\frac{I_{C S P}(n, t+1)}{S C_{C S P}(n, t+1)}\right)}{\beta}\right)^{\gamma}\right)$,

$T K(t+1)=T K(t)+\sum_{n} \frac{I_{C S P}(n, t)}{S C_{C S P}(n, t)}$.

We choose a one factor learning curve in order to model the learning-by-doing effect, as the literature suggests that the main decrease in costs for CSP plants will be related to an increase in experience and deployment, more than to basic R\&D (Arvizu et al. 2011; Bosetti et al., 2012). By not taking into account all productive areas in the world we possibly underestimate the learning effect.

The saturation term limits the expansion of CSP in any given year within reasonable rates. It works similarly to a technology penetration constraint, but it has greater flexibility because it does not impose a fixed limit. For $\gamma>1$, the cost aggravation is very modest when installed capacity is well below the threshold $\beta$; when installed capacity is equal to $\beta$ the cost doubles; when it exceeds $\beta$, the cost penalty increases substantially. Calibration details are discussed in the Section 4.

\section{Technical assumptions and calibration}

CSP plants are either of the linear focus or the point focus type. Parabolic trough power plants belong to the family of linear focus plants and are the most common type. They are characterised by arrays of parabolic reflectors that concentrate incident solar radiation on to an absorber, positioned in the focal line of the concentrator. Oil is circulated through the absorber and heated up to $390{ }^{\circ} \mathrm{C}$. The oil is then collected to generate steam used in a conventional turbine generator (Arvizu et al., 2011). The collectors can track the sun diurnal course to maximize efficiency. In CSP of the point focus type, solar radiation collected by a series of concentric mirrors is concentrated into a single receiver, usually placed on a tower (power tower). Temperatures of more than $1,000{ }^{\circ} \mathrm{C}$ can be achieved, as in the most advanced gas turbines. $^{7}$

\footnotetext{
${ }^{7}$ Linear Fresnel reflectors and dish systems are two minor types of linear and central focus CSP plants (Arvizu et al., 2011).
} 
Both plant types can store heat to generate a constant flow of steam and of electricity. Trough plants can already achieve 6-7.5 hours of storage (Arvizu et al., 2011), while central receiver plants can store heat even more efficiently. An experimental plant in Spain is designed to achieve up to 15 hours of heat storage (Arce et al., 2011).

Despite their attractiveness, solar towers are still at their early phase of development. Therefore in this study we focus on parabolic trough power plants for which more is known about market costs (Richter, 2009). ${ }^{8}$ We set investment cost at 6,500 USD per $\mathrm{kW}$, assuming integrated thermal storage units for seven hours; operation and maintenance costs are equal to 127.5 USD per kW (Kaltschmitt et al., 2007). These costs are in line with those expected from the latest Californian development project: the Blythe Solar Power Project (Streater, 2010). The Special Report on Renewable Energy (SRREN) of the IPCC finds that capital costs are in the range of 6,000 to $7,300 \mathrm{USD} / \mathrm{kW}$ and operation and maintenance costs in the range of 60 to $82 \mathrm{USD} / \mathrm{kW}$ (Bruckner et al., 2011).

The number of hours of clear sky and atmospheric conditions have a great influence in determining the level of DNI that a production site receives. We use data on DNI from the U.S. National Renewable Energy Laboratory (NREL) estimates, available from the NASA Atmospheric Science Data Center. ${ }^{9}$ For MENA, we consider delocalised production in different sites in the Sahara Desert region as currently discussed (Trieb, 2006; Trieb and Müller-Steinhagen, 2007); for China we have chosen the Tibet area around the city of Xigaze, as one of the options described in Chien (2009), and for the USA we consider production in Arizona, around Phoenix, the most productive part of the country. The number of full load hours of operation per year is taken from Trieb (2009b) and Kaltschmitt et al. (2007). We use an annual depreciation rate of $10 \%$, which corresponds to a power plant lifetime of 20 years. Further details are provided in Table 1.

[Table 1 approximately here]

Table 1 also shows the cost of electricity generated with CSP in the producing regions, under alternative interest rates. Our costs are close to the upper bound of the interval found in the Appendix III to the SRREN report (Bruckner et al., 2011), for the 3\%,7\% and 10\% interest rates. However, unlike Bruckner et al. (2011) we do include the cost of the grid to transport electricity from remote production sites to consumption sites (except for MENA, where favourable production conditions exist near consumption sites).

An important feature of WITCH is that the cost of electricity is not an exogenous input in the model - as for the great majority of integrated assessment models with energy modules separated from the

\footnotetext{
${ }^{8}$ Existing plants include the SEGS plants in California, Nevada One in Nevada and the Andasol Plants in Spain. Installed capacity in 2009 was 500 MW, while under-construction or proposed capacity currently exceeds ten thousand MW (Arvizu et al., 2011).

${ }^{9}$ Available at: http://eosweb.larc.nasa.gov/ . This dataset uses NREL's Climatological Solar Radiation (CSR) Model which accounts for cloud cover, atmospheric water vapor, trace gases, and aerosol in calculating the insulation with measurements checked against ground stations where available.
} 
economy. ${ }^{10}$ The interest rate emerges endogenously as the shadow value of capital in WITCH. The interest rate reflects the productivity of capital under alternative uses, both in the present and in the future. The remuneration of capital realistically differs across countries, according to their level of development. Generally, developing countries have higher interest rates because their marginal productivity is higher than in developed countries. Analogously, the interest rate in developing countries falls as they get richer. The implication is that investments in power plants with high capital requirements are more costly in developing countries than in developed countries, and in the future capital-intensive generation technologies become relative cheaper than fuel-intensive technologies.

At the bottom of Table 1 we report the endogenous interest rate in China, MENA and the USA in 2010 and 2050 and the cost of CSP generation calculated using the endogenous interest rates and assuming that investment cost remains stable at 6,500 US\$/kW. Even without accounting for learning effects, from 2010 to 2050 CSP electricity cost drops by $32 \%$ in China, $11 \%$ in the USA and by $5 \%$ in MENA.

Technological progress reduces the cost further. CSP is a proven technology at the utility scale. Cost reduction will come from incremental improvements rather than from major technological breakthroughs. New fluids to capture, transmit and store heat can boost efficiency. The collector is the largest area for potential cost reductions, whereas the thermodynamic components of the plant already benefit from the knowledge developed in other thermal power plants (Arvizu et al., 2011).

The nature of the technological progress in the CSP industry justifies the adoption of one-factor global learning curves. We use a learning ratio of 10\% (Arvizu et al., 2011; IEA, 2010c; Neij, 2008; Ummel and Wheeler, 2008). This means that investment costs are reduced by $10 \%$ at every doubling of the installed capacity. Estimates of the learning ratio in the literature vary from 15\% to 8\% (Arvizu et al., 2011; Enermodal Engineering Limited, 1999; IEA, 2003, 2010c; Kearney, 2003; Neij, 2008; Williges et al., 2010). A wider range of learning ratios is tested in the sensitivity analysis.

The learning process occurs as an externality. Therefore, countries benefit from the positive technological externality but do not govern it. However, WITCH is a perfectly forward looking model and countries exactly forecast the technology options and costs that they will face in the future.

We do not have empirical evidence to calibrate the cost aggravation term in equation (11). We fix $\gamma$ equal to 3 and $\beta$ equal to $380 \mathrm{GW}$. This means that the construction of $10 \mathrm{GW}, 180 \mathrm{GW}$ and $500 \mathrm{GW}$ of power generation capacity over five years (the time-step of our model) bears an aggravation equal to $0.002 \%$, $10.6 \%$ and $227.8 \%$, respectively. ${ }^{11}$ There is of course some arbitrariness in the choice of these parameters. Thus, we test our choices with a sensitivity analysis and find that the results are robust.

\footnotetext{
${ }^{10}$ The decision variable in WITCH is the amount of investment in each technology, at any point of time. Leontief-type production functions associate to investments the highest amount of electricity that can be generated for that amount. These functions are calibrated using the technical parameters of power plants (efficiency, capital costs, fuel use, operation and maintenance costs, etc.).

${ }^{11} 1 \mathrm{GW}$ is roughly the power capacity of a large coal power plant; the cumulative global CSP installed capacity in 2012 is equal to $1.9 \mathrm{GW}$, mostly consisting of parabolic troughs plants.
} 
HVDC cables connect the remote areas where electricity is generated to major consumption areas. ${ }^{12}$ Estimates of investment costs for such infrastructure vary in the literature and depend on the characteristics of the cables: voltage, power capacity and overhead/submarine. We consider cables with $5 \mathrm{GW}$ of power capacity and +/- $800 \mathrm{kV}$ voltage. We extrapolate costs from May (2005) and Trieb (2006) and we provide detail in Table 1.

For the Europe-MENA interconnection we assume connecting power lines of $3000 \mathrm{Km}$ (Bauer et al., 2008; Czisch, 2004; Trieb, 2006). One fourth of the connection lines is submarine, the rest is overhead. Such lines would allow the connection of the most northern parts of the Sahara with Scandinavia or more inland areas with the centre of Europe. For China we consider overhead transmission lines equal to 2800 $\mathrm{Km}$, calculated as the average between the distances of Xigaze from three of the major industrial centres: Beijing, Shanghai and Guangzhou. For the USA, we assume the transmission of the electricity generated to be split in half between the West coast and the East coast. Considering Phoenix, Los Angeles and New York as reference points this entails overhead transmission lines of 577 and $3447 \mathrm{~km}$ respectively.

We assume that CSP electricity enters the CES production nest illustrated in Figure 1 in different nodes in different regions. In MENA, CSP enters as a perfect substitute of either oil or gas electricity, as these are major power generation sources in the region. In all other regions, CSP electricity enters as a perfect substitute of either nuclear power or coal (both with and without CCS). We focus on nuclear and coal because their expansion may be limited by issues of public acceptability and CSP could provide a valuable alternative.

All regions without the CSP option still have a generic electric backstop technology that enters as a substitute to nuclear power.

\section{Scenario design}

We analyse a Business-as-Usual ( $\mathrm{BaU})$ scenario where no climate policy is in place and four climate policy scenarios in which GHG concentration cannot be higher than $535 \mathrm{ppm} \mathrm{CO}$-eq in 2100 . This requires that global emissions are 33\% lower than the 2005 level in 2050 and $51 \%$ in 2100 . The stabilization scenarios have different assumptions on the availability of nuclear power and IGCC coal power with CCS, as detailed in Table 2. In order to study the role of CSP in climate mitigation we build four corresponding cases in which it is not possible to invest in CSP to use as counter-factual. We also analyse a scenario with forced earlier investments in CSP to evaluate the benefits of a coordinated action to anticipate investments in this technology (see Section 7).

[Table 2 about here]

\footnotetext{
${ }^{12}$ Transmission power losses are in the range of $3 \%$ for $1000 \mathrm{Km}$, while HVDC terminal losses are $0.6 \%$ per inlet or outlet station (May, 2005). Power transmission over distances of $3000 \mathrm{Km}$ entail transmission losses around $10 \%$, while high voltage alternating current (HVAC) cables would cause power losses of around $20 \%$ and higher investment costs (Breyer and Knies, 2009).
} 
All of the above scenarios include the possibility for the USA, China and MENA to produce and domestically consume CSP electricity and for E-EU and W-EU to import from MENA. Moreover, all scenarios include a constraint on domestic renewable sources: regional wind and solar photovoltaic electricity generation cannot exceed $25 \%$ of the total regional generation to limit the penetration of intermittent electricity sources. ${ }^{13}$

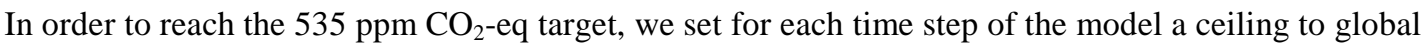
GHG emissions consistent with the concentration target in 2100. The model allows for spatial flexibility but it does not allow intertemporal flexibility. Therefore we might overestimate the cost of imposing technological constraints. To be able to achieve such emission targets, the twelve regions of the model have the possibility of undertaking the following actions: ( $i$ ) reduce consumption of energy; (ii) change energy mix; (iii) trade emission permits in a world carbon market; (iv) reduce emissions from LULUCF and emissions of non- $\mathrm{CO}_{2}$ gasses. ${ }^{14}$

\section{Results}

This section explores simulations results and focuses on (i) the optimal timing and size of CSP power generation, (ii) investments and cost dynamics, (iii) the Europe-MENA trade of electricity from CSP, (iv) the impact of CSP on the energy mix, (v) the option value of CSP, and (vi) it assesses the feasibility of the foreseen expansion of CSP.

\subsection{The optimal timing and size of investments in CSP}

Our results show that it is optimal to invest in CSP under various scenarios. In particular, we find that for MENA CSP is not only a valid mitigation strategy, but it is an economically viable generation technology even in the absence of climate policies (Figure 2).

[Figure 2 about here]

For MENA, it is optimal to invest in CSP from 2075 even without the climate policy. Investments start in 2035 (power generation in 2040) under all stabilization policy scenarios and are higher in the scenarios with constraints to nuclear power and IGCC coal with CCS. In the USA and China it is instead not optimal to invest in long distance CSP without the climate policy. In the climate policy scenarios with technological constraints, generation starts from 2040-2045, when the global price of carbon is equal to

\footnotetext{
${ }^{13}$ Note that this $25 \%$ limit does not apply to the CSP electricity. Without limits to the penetration of wind and solar photovoltaic - and without constraints to either nuclear or IGCC with CCS - there is no demand of CSP electricity from E-EU and W-EU. CSP is instead used in MENA, in China and in the USA, but production starts later in the century.

${ }^{14}$ The allocation of carbon permits follows a "contraction and convergence" rule, which assigns global emissions targets to each region, initially in proportion to current emissions and then, progressively, in proportion to each region's population, with the aim of reaching similar per-capita emissions by the end of the century (Meyer, 2000). The distribution of permits affects only the distribution of stabilization costs and alternative allocation rules would therefore leave unchanged investment decisions in CSP as well as in other technologies (Coase, 1960). Minor changes would appear in case of strong revenue effects.
} 
$175-200 \mathrm{US} \$ / \mathrm{tCO}_{2}$-eq while, in the unconstrained scenario, in 2050 it becomes competitive with nuclear and IGCC coal with CCS (price of carbon equal to $492 \mathrm{US} \$ / \mathrm{tCO}_{2}$-eq).

In absolute terms, China is the region with the largest production of CSP electricity, followed closely by the USA. This is explained by the growing size of the Chinese economy, which, in our BaU scenario, reaches the size of the US economy at the end of the century. Recall that the total quantity produced by MENA shown in Figure 2 includes both domestic consumption and export to Europe.

Simulations show that the U-Stab scenario converges to the CC-Stab scenario and the NC-Stab scenario tends to the NCC-Stab scenario; this is related to the fact that the attractiveness of CCS in the electricity mix decreases towards the end of the century due to a capture rate lower than one (set at $90 \%$ in line with current technological predictions). Domestic consumption of CSP for MENA is not very sensitive to the different policy scenarios because nuclear power and CCS are not major technological options in the region (Figure 6); the differences in Figure 2 mostly depend on the variance of demand from Europe.

[Figure 3 about here]

For what concerns the SG infrastructure needed to transmit the electricity generated, we have assumed the construction of HVDC cables able to transmit the maximum amount of generated CSP. ${ }^{15}$ Therefore, the needed SG installed capacity for China and the US can be read from the right-hand side of the graphs of Figure 2 that report CSP installed capacity. Figure 3 instead shows the installed capacity of SG infrastructure that is needed to allow the export of CSP electricity from MENA to Europe. The sensitivity of the needed amount of connecting infrastructure is again strongly related to the assumptions on the future expansion possibilities of nuclear power in Europe. Indeed, if nuclear power will not be able to penetrate the market above 2005 levels, the demand for CSP electricity will, according to our simulations, more than double, compared to the results of the corresponding scenarios with no limit on nuclear power.

\subsection{Investments and cost dynamics}

Figure 4 reports the investments in billions of US\$ necessary to build in MENA (including capacity and grid for exports to Europe) and in the USA the CSP and SG capacities depicted in Figure 2 and 3. China follows a pattern similar to that of the USA. While installed capacity increases constantly, the amount of investments remains rather stable from 2060 onwards. This happens because investment costs decline as the global cumulative installed capacity increases.

The investments needed for the construction of the SG infrastructure are significantly lower than those for the generation power plants and range between 1-9\% of the total investment costs for MENA, and 5-15\% for the USA. Their share increases over time as we have assumed non decreasing investment costs for the SG infrastructure.

\footnotetext{
${ }^{15}$ Recall that we do not model daily or seasonal trends but global annual generation for 5 year time steps.
} 
The cost paths depicted in the left panel of Figure 5 represent the weighted average of the costs across regions that we obtain for the four policy scenarios. ${ }^{16}$ Investment costs drop quickly as global installed capacity increases. In the first ten years during which investments in CSP occur the cost drops by at least $50 \%$. Eventually the cost reaches a floor of about $1,500 \mathrm{US} \$ \mathrm{~kW}$. Therefore, the major reason for postponing investments in CSP is the presence of cheaper abatement possibilities. The online Appendix reports the costs of all electricity generation technologies, divided into capital, fuel and $\mathrm{CO}_{2}$ emissions components that emerge from our simulations as a useful reference.

\subsection{The Euro-MENA trade of CSP electricity}

Our results also show that a SG that connects the power networks of MENA and Europe becomes remunerative in the CC-Stab and the NCC-Stab scenarios from 2045. Without constraints to nuclear and/or IGCC coal with CCS, the Mediterranean SG becomes an attractive option from 2060 onwards. Figure 7 shows how the total CSP electricity generated by MENA is divided between domestic consumption and exports to E-EU and W-EU. We find that: $(i)$ most of the electricity produced is for domestic consumption, (ii) electricity directed to W-EU is higher than towards E-EU, but imports represent a greater share of E-EU electricity consumption (see Figure 8) and in value, a relative greater portion of E-EU gross domestic product (GDP) (Table 3), (iii) both domestic consumption and exports increase over time, but exports are more sensitive to the technology scenarios. This is mainly due to the fact that MENA has low levels of generation with both nuclear and IGCC coal with CCS power plants.

The fact that the largest part of CSP production by MENA is for domestic consumption is an important result from a policy point of view. Indeed, it is optimal to build CSP plants first for domestic reasons and then as an export opportunity. The attractiveness of CSP would increase if large desalinization projects were to increase demand for energy, and if the price of natural gas and of oil was to increases faster than what prospected in our scenario.

Figure 6 shows the market clearing price for the Euro-MENA CSP electricity trade under the different scenarios. The price has a decreasing trend that is related to investment costs. It starts - in the most extreme case - from just over $30 \mathrm{c} \$ / \mathrm{kWh}$ and decreases to $10-11 \mathrm{c} \$ / \mathrm{kWh}$ at the end of the century. The large price differences at the beginning of the trade are due to the different costs of production that arise for the different scenarios.

Table 3 reports the market size of the trade between MENA and Europe. Money flows are reported in absolute values and in relative terms with respect to regional annual GDP. Indeed, our simulations indicate that starting from 2055, this trade builds up a market of several hundreds of billions of US\$. More in detail, imports from W-EU reach $0.6 \%$ of the regional GDP, and $1.6 \%$ in E-EU. For MENA the export of CSP electricity generates revenue that accounts for between $0.8 \%$ and $2.7 \%$ of the regional GDP. As a reference, consider that total fuel imports by EU-27 were equal to 192 US $\$$ billions in 2009, or

\footnotetext{
${ }^{16}$ This is the average of the regional costs weighted by the amount of production of the region. There are some differences in the regional investment costs due to the component of the investment cost that mimics short term frictions (see Eq. 3).
} 
$1.3 \%$ of GDP, and that total fuel exports of the Middle-East (not including Northern African countries) were equal to 437 US\$ billions in $2009,68 \%$ of merchandise exports. ${ }^{17}$

The investments needed for the construction of the SG infrastructure, necessary to allow this trade, range between 1-26 billion US\$ per year in absolute terms and, in relative terms, between $0.02-0.27 \%$ of the GDP of MENA. Therefore, the annual investment effort needed for the deployment of the CSP capacity and the SG appears within the financing possibility of MENA countries, thus, funding from European partners or from international organizations does not seem crucial.

\subsection{The impact of CSP on the electricity mix}

CSP power enters as a substitute of oil and/or gas power plants in MENA and as a substitute of IGGC coal with CCS and/or nuclear power in China, E-EU, W-EU and the USA. Figure 8 displays the optimal switching strategy. In the MENA region, CSP substitutes both oil and natural gas power plants. In E-EU, W-EU and China, CSP substitutes nuclear power only if limits on penetration are imposed. This reveals a high option value for nuclear power in those regions. In the USA, CSP substitutes nuclear power even without limits on its expansion because the CSP is relatively less expensive than in other regions (see Table 1, the Appendix and the online Appendix).

Although CSP is in direct competition with only two specific generation alternatives for each region, it can ultimately substitute all generation sources by changing the optimal technology mix (Figure 1). Figure 9 shows the electricity mix of the five regions that we are studying together with the global electricity mix.

In W-EU, in the BaU scenario, the main sources of electricity are fossil fuels (in particular coal and gas), nuclear power, and renewable sources. Over time there is a contraction in the electricity share of gas, oil and coal and an increase in the share of wind and solar PV (W\&S). Nuclear power remains fairly stable. A climate stabilization policy (without technological penetration limits) induces a contraction of all fossil fuel sources, especially coal, the introduction of IGCC with CCS, an expansion of nuclear and of W\&S. When generation constraints on nuclear power are introduced, the latter contracts and the share of hydrocarbon sources (especially IGCC with CCS where it is allowed) increases until imported CSP starts to have a relevant share in the mix. When IGCC production with CCS is not allowed the nuclear share expands significantly. By the end of the century, the W-EU electricity mix is dominated by three main sources: nuclear, domestic renewable power including hydroelectric power, and imported CSP power. In particular, in the scenarios where limits on nuclear power expansion are imposed, CSP imports become the single most important electricity source.

In E-EU the electricity mix in the $\mathrm{BaU}$ scenario is dominated by coal power. Therefore, IGCC coal power plants have a much greater role than in W-EU in the policy scenarios. Nuclear is the dominant abatement technology at the end of the century, when carbon leakages from CCS are heavily penalized. For this

\footnotetext{
${ }^{17}$ Data from tables II.2, II.5 and the trade profiles of the International trade statistics 2010 publication by the WTO, expressed in 2005 US\$. For an analysis of the contraction of revenues from oil trade in a stabilization scenario see Massetti and Sferra (2010).
} 
reason imported CSP has a great role to play after 2050 in those scenarios where nuclear power is limited. By the end of the century, with climate policy, electricity production is based on nuclear power and on domestic and imported renewable sources.

In MENA the BaU electricity mix is dominated by gas generation until 2050. After 2050, high gas prices and cost reductions in CSP plants make it optimal to use solar power plants even in the BaU. With the climate policy in place, this trend is reinforced and the CSP share of total electricity generation reaches $90 \%$. There might be technical limits to very high penetration shares, but the possibility to store heat for many hours and/or to use hybrid CSP-natural gas power plants supports our findings (IEA, 2010b; Trieb, 2009a; Trieb and Müller-Steinhagen, 2007).

In the United States, coal, nuclear power and gas generate most of the electricity in the BaU scenario. With climate policy, IGCC with CCS and nuclear power - where available - or gas generate the largest fraction of electric power. Around 2050 renewable sources drastically increase their share of electricity generation, especially long distance CSP. By the end of the century, CSP generation covers $70 \%$ of electricity generation.

In China the electricity mix is dominated by coal and hydro-electric power in the BaU. With the stabilization policy, pulverised coal is substituted by IGCC with CCS and nuclear power, where these technologies are available. From 2050 it becomes optimal to generate electricity with CSP that reaches very large shares by the end of the century. Interestingly, nuclear is a "bridge" technology in our U-Stab scenario and decreases in share after 2050.

If we compare the electricity levels depicted in Figure 9 to those of the corresponding scenarios without long-distance CSP, we find that this technology has a great potential for electrification. ${ }^{18}$

\subsection{The option value of CSP}

In this section we assess the value of CSP as an alternative power technology option. We define the increase in mitigation cost that occurs when a technology is not available relative to the scenario with the technology as the stabilization-cost option-value. ${ }^{19}$

[Table 4 about here]

Table 4 displays estimates of the option value of CSP when nuclear power and IGCC coal with CCS are available or restricted. The table also reports the estimated option value of nuclear power and IGCC coal with CCS when CSP is either available or not.

\footnotetext{
${ }^{18}$ More in detail, aggregating over time we find that for W-EU having the possibility to import CSP from MENA via a SG induces a higher use of electricity (+4\% in U-Stab, $+18 \%$ in NC-Stab, $+2.5 \%$ in CC$\mathrm{Stab},+45 \%$ in NCC-Stab). For E-EU the increase ranges between $4 \%$ in the U-Stab scenario and $54 \%$ in the NCC-Stab scenario. For MENA, electricity consumption increases from 24\% (U-Stab) to 58\% (NCC$\mathrm{Stab}$ ), maintaining the same level of economy-wide GHG emissions. For USA and China, these values range from $6 \%$ to $77 \%$ and from $7 \%$ to $84 \%$, respectively.

${ }^{19}$ We use a global cap-and-trade policy tool without banking and borrowing. This implies that mitigation is efficient across space (there is one single global price of carbon) but not necessarily across time. By
} 
Indeed, the stabilization cost option value of CSP in all regions excluding MENA ranges between $0.1 \%$ and $1.1 \%$ of discounted GDP in the U-Stab scenario, from $0.1 \%$ to $2.0 \%$ in the NC-Stab scenario, from $0.1 \%$ to $1.8 \%$ in the CC-Stab scenario and from $0.4 \%$ to $3.4 \%$ in the NCC-Stab Scenario. CSP is a relatively less attractive option in W-EU because the share of coal power is relatively low and the share of nuclear power is relatively high (recall that the NC-Stab scenario is not a phase-out scenario: it constraints nuclear capacity to 2005 levels).

The possibility to import electricity from CSP power plants in the MENA region decreases the stabilization policy costs by between 5 and 27\% for Western Europe and between 6 and 27\% for Eastern Europe, compared to the corresponding policy cases without the CSP option (see Table 4). For the USA and China, these policy costs are reduced by $12-37 \%$ and $25-47 \%$, respectively. MENA reduces its losses by between 44 and $66 \%$.

For what concerns the option value of nuclear power and IGCC coal with CCS, our results indicate that when CSP is available, the stabilization cost option value of nuclear power and IGGC coal with CCS, separately or jointly, is reduced greatly, especially in China and in the USA. The stabilization cost option value of MENA is negative because the region gains from exports of CSP to Europe. CSP reduces the option value of nuclear more than of coal power.

\subsection{Comparison with the literature and discussion}

The scenarios discussed in Section 6 indicate that it is not optimal to invest in CSP generation before 2035 for all three producing regions. Significant investments should occur only from 2050 onwards.

Many non-peer reviewed studies though, suggest that investments should start much earlier, around 20202030, as reported in Table 5 (IEA, 2008, 2010a, 2010c; Richter, 2009; Trieb, 2006, 2009a; Trieb and Müller-Steinhagen, 2007; Ummel and Wheeler, 2008). Some studies see a potential for CSP trade also in a world without climate policies (Richter et al., 2009). Krey and Clarke (2011) examine 57 climate policy scenarios from the recent IAM literature to assess the importance of alternative mitigation technologies. They divide the scenarios in three broad classes: the BaU scenario, a moderate climate policy scenario (440-660 ppm $\mathrm{CO}_{2}$ only) and a stringent climate policy scenario ( $<440 \mathrm{ppm} \mathrm{CO}_{2}$ only). Table 5 displays the median values of electricity generation with CSP for each scenario class.

Our study (535 ppm CO $\mathrm{CO}_{2}$-eq, -30\% of global emissions in 2050 wrt 2005) falls in the moderate climate policy category. With respect to the literature our scenarios indicate that it is not optimal to invest in CSP electricity in the first part of the century, without climate policy. Instead, if there are constraints to the penetration to nuclear and/or IGCC coal with CCS, the scenarios indicate that it is optimal to invest in CSP as much, and sometimes above, what predicted by the non-peer reviewed literature and by several IAM scenarios. ${ }^{20}$

reducing the flexibility of allocating abatement across time we might overestimate the cost of introducing technology constraints. As a consequence, the option value of CSP might be overestimated as well.

${ }^{20}$ Some studies surveyed by Krey and Clarke (2011) also include technological and/or political constraints. Therefore the comparison is not straightforward. 
The model has enough flexibility to induce a large use of CSP. However, without climate policy and without constraints to other base-load, low-emission, power generation technologies it is generally not convenient to invest in CSP. CSP is a niche technology, for areas in which the DNI is high, when the price of fossil fuels increases considerably. The large subsidies that are driving CSP capacity expansion corroborate our hypothesis (Feed-In tariffs are: France $30 €$ cents/kWh, Spain $27 €$ cents/kWh, Italy 22$28 €$ cents/kWh, India 19 US\$ cents/kWh, Turkey 24-20€ cents/kWh. Source: Richter et al., 2009). In the long-term instead, especially under climate policy with constraints on nuclear power or on IGCC coal with CCS, CSP becomes an economically viable alternative and generation capacity expands enormously. It is important to assess if these production levels can be implemented in practice. We consider two potential limits: space and the complexity of the grid infrastructure.

A large deployment of CSP electricity generation and its transmission over long distances to reach consumption sites necessarily implies a large footprint in terms of land and infrastructure (see Table 6). If we compare the total surface of the Sahara desert to the portions needed for the CSP mirrors in MENA for domestic consumption and export to Europe, we find that the latter, although very large, correspond to about 3/1000 and 1/1000 of the available surface, respectively. Therefore availability of space does not seem a problem in the MENA region. In the USA instead, the surface for the largest expansion of mirrors would require $0.26 \%$ of total land in the contiguous 48 States, corresponding to about $6 \%$ of land in Arizona; in China, $2 \%$ of Tibet should be used to host CSP power plants. It is not clear if this large footprint is actually feasible or not.

Table 6 also reports the number of 5GW HVDC cables that would need to be installed for the transmission of CSP electricity within the USA, within China and between MENA and Europe. Notice that the number of 5GW cables needed is very high (up to 500 in China, in 2100), especially if compared to the existing or planned interconnections. In 2011 the capacity of the highest intra-European interconnection was equal to 6GW; in 2050, the renewable-friendly European Climate Foundation Roadmap 2050 foresees an interconnection capacity of 47GW between France and Spain (ECF, 2010). Investments for increasing the interconnections of distant areas are taking place at national or international levels. Examples of underway HVDC investment projects are found in Germany, Finland, the UK, the USA, China, Brazil, India, New Zeeland, and between Germany and Norway, and France and Spain. ${ }^{21}$ The power grid is still very fragmented in the U.S. (Joskow 2012). Therefore, our scenarios with the highest penetration of CSP pose engineering and administrative challenges for the authorization, implementation and management of the power grid.

\footnotetext{
${ }^{21}$ Information on these projects may be retrieved on different websites including: http://www.reuters.com/search?blob=hvdc; http://www.energy.siemens.com/entry/energy/hq/en/; http://www.abb.com/industries/it/9AAF400191.aspx?country=GB; http://www.rockislandcleanline.com; https://www.transpower.co.nz/projects/hvdc-inter-island-link-project, last accessed on February 172012.
} 


\section{Early investments in CSP}

In the sensitivity analysis (online Appendix) we examine how the optimal timing of investment in CSP changes with alternative assumptions on capital cost. We find that when the cost of CSP drops by 30\%, investments occur earlier than in the central case, but always later than in other studies. Therefore, other studies must assume at least one of the following options: (i) much lower capital costs of CSP and SG (also thanks to subsidies), (ii) much higher costs or limits to the penetration of other carbon free electricity generation technologies, (iii) less opportunities for energy efficiency improvements, (iv) other non-tangible benefits or positive spillovers.

In this Section, we focus on the latter explanation and we examine the role of learning externalities. It must be recalled that the standard solution of WITCH is the outcome of a non-cooperative game. Since the cost of CSP is governed by a one-factor global learning curve, regional social planners do not internalize the knowledge spillovers and invest less - and later - than what it would be socially optimal (See Equation 12). Would it be socially desirable to force countries to invest more and earlier in CSP $?^{22}$ We assume that MENA, China and the USA introduce a coordinated policy that forces the investments in CSP to be above a minimal threshold from 2010 until 2030. This threshold is different for all regions and varies over time in order to replicate the investment pattern in CSP found in the "New Policies Scenario" of the World Energy Outlook 2010 (IEA, 2010c). According to this scenario China and the Middle East deploy $17 \mathrm{GW}$ of CSP in 2035 and the USA $12 \mathrm{GW}$. The target is to stabilize GHG concentrations at 535 ppme by 2100 , with no limits to the penetration of nuclear or IGCC with CCS power ("Early-U-Stab").

[Figure 10 about here]

The Early-U-Stab scenario shows that a more rapid expansion of CSP determines a faster contraction of investment costs than in the U-Stab scenario, due to learning-by-doing (Figure 10). However, after 2050 the learning effect vanishes and the cost curves converge. After 2030 the USA and China stop investing, while MENA keeps adding CSP capacity. When the USA and China resume investments in 2045, they add much more capacity than in the U-Stab scenario because the cost of CSP is lower. However, they rapidly converge to the investment pattern of the U-Stab scenario. CSP electricity trade with Europe starts five years earlier, in 2055 .

The forced anticipation of investments has positive welfare effects. MENA, CHINA, the USA and Europe have higher discounted welfare than in the U-Stab scenario. The policy acts as a coordination mechanism and internalizes the learning externalities. However, the discounted consumption gains with respect to the U-Stab scenario are very small: $+0.16 \%$ ( $5 \%$ interest rate) or $+0.24 \%$ (3\% interest rate) in MENA; much lower in all other regions.

Therefore, learning externalities might motivate the introduction of moderate subsidies to invest in CSP in countries with high production potential. However, they do not suggest that it would be optimal for

\footnotetext{
${ }^{22}$ Externalities within each region are instead fully internalized.
} 
Europe to import CSP electricity before the second half of the century, nor they suggest that large early expansions of CSP would be optimal. ${ }^{23}$

\section{Building a Mediterranean power market: energy security and regulation Issues}

In this section we argue that the functioning of a large Mediterranean power market might not be as smooth as assumed in the previous Sections and by the rest of the literature for two main reasons: (1) large imports of electricity from the MENA region might affect the security of the European power market and (2) producing countries might have the incentive to form a cartel to sell electricity at prices higher than the marginal cost. Without a strong international effort to build trans-Mediterranean cooperation and international institutions to regulate the power market, the risks might outweigh the benefits.

\subsection{Energy security}

In our scenarios, CSP electricity covers from $18 \%$ to $46 \%$ of total electricity consumption in Europe. The Desertec concept foresees $17 \%$ of electricity consumption to be provided by the MENA region in 2050.

In Bauer et al. (2008) electricity from the MENA region covers about one-third of electricity consumption in Europe. These large shares of imported electricity pose a technical and political challenge for the European power market, which is now practically self-sufficient. Particular attention must be paid to avoid negative repercussions from disruptions in the power supply from MENA countries. A sudden collapse of supply would put the whole European network under stress. A large share of imported CSP therefore requires costly investments in back-up capacity, which reduce the convenience of transfering displace electricity generation in the MENA region. ${ }^{24}$ Analogously, MENA countries would face the dangerous situation of depending on one single market for exports.

\subsection{Market regulation}

The creation of a large trans-Mediterranean market for electricity requires the establishment of an international regulatory agency to oversee the functioning of the super-grid and to ensure the highest possible level of market competition. We believe that the discussion of the institutional aspects of a large Mediterranean grid should be moved on top of the agenda, before any large investment project starts. It is not unrealistic that a future Europe-MENA trade could become a bilateral monopoly, with both monopoly and monopsony features. Therefore, market price and output will likely be determined as the outcome of

\footnotetext{
${ }^{23}$ With constraints on the expansion of nuclear and CCS trade could start earlier, but the literature assumes (at least implicitly) scenarios without constraints on specific technologies.

${ }^{24}$ The Desertec concept is very optimistic on the development pattern of Northern Africa and assumes that the South Mediterranean region will have roughly the same economic power of Europe in 2050 (http://www.desertec.org/en/concept/questions-answers/\#c809). Trieb (2006), instead recognizes that trade of electricity across the Mediterranean scenario will not become reality automatically. A developmental path "enlarging the gap" is not an exotic fiction, according to Trieb (2006).
} 
an international bargaining process. A badly regulated market can cause serious international frictions and might eventually jeopardize the establishment of the market itself.

In particular, countries part of the MENA aggregate might have the incentive to form a cartel to sell electricity at prices higher than the marginal cost. This hypothesis is not unrealistic and is supported by the historic ties that many MENA countries have in the Organization of Petroleum Exporting Countries (OPEC). This Section tests this hypothesis.

In the standard solution of WITCH, all regions are "price takers", i.e. they are not able to excerpt any market power. This implies that in all the scenarios examined in the previous sections, MENA exports electricity at a price equal to its marginal cost. Those scenarios constitute the best possible market structure for Europe. In order to test if MENA countries have the incentive to build a cartel, we prepared an additional set of scenarios. Instead of letting supply and demand forces determine the market price, in these new scenarios we fix the price of CSP electricity and we let demand adjust to it. It is important to note that the returns to scale to the CSP industry are linear, with space not being a limiting factor. Therefore supply can support any level of demand if the price is above the marginal cost. If the price is below the marginal cost supply goes to zero. If the price of electricity is too high, demand drops to zero because alternative carbon-free power generation options in Europe become more affordable. The left panel of Figure 11 displays the minimum and the maximum price vectors for which a Mediterranean market for CSP exists. Since we do not pose any constraint to the deployment of nuclear power and CCS, the minimum price (p-min) is equal to the price in the U-Stab scenario.

[Figure 11 about here]

All combinations of prices and the corresponding quantities traded, included in the grey area, are Pareto improving compared to the corresponding simulations where CSP trade is not allowed. We tested three intermediate trajectories of prices.

We find that as price increases the quantity traded decreases and therefore both revenues and costs decrease in the MENA region (see the right panel of Figure 11). Profits, defined as the difference between revenues from CSP sales and costs to generate and transmit electricity, follow an inverted-U relationship with prices of electricity because demand in Europe - in particular in W-EU - is quite elastic in our model as domestic carbon-free options are available.

On welfare grounds, MENA's consumption and welfare levels also follow an inverted-U relationship with prices of electricity, and reach their maximum between $\mathrm{p} 2$ and $\mathrm{p} 3$. Therefore, compared to the competitive equilibrium case, MENA is better off with prices between p2 and p3. W-EU and E-EU are instead better off in correspondence with the minimum price vector where they are able to import a larger amount of zero-carbon electricity at lower prices. If the market will not be perfectly competitive, the exact exchange price will depend on the bargaining power of the three regional blocks. 
The proponents of the Desertec concept do not believe that MENA countries might form a cartel because Europe has the potential to generate CSP domestically and would discourage any monopoly. ${ }^{25}$ We show here that there are instead incentives for MENA countries to behave as a block and to supply electricity at a price above the marginal cost. However, prices cannot increase too much because Europe can expand the domestic supply of electric power from nuclear, coal with CCS and renewables. Of course, the bargaining position of Europe gets weaker if the deployment of nuclear power and CCS is limited.

\section{Conclusions}

This paper examines the effects of introducing Concentrated Solar Power (CSP) transmitted by means of Super-Grids (SG) in five regions of the world: China, Eastern Europe (E-EU), Western Europe (W-EU), the Middle East and North Africa (MENA) and the United States of America (USA). The Integrated Assessment Model WITCH is used to perform a numerical assessment of the economic and technological potential of CSP and its transmission over long distances.

The analysis of the simulation scenarios shows that $(i)$ an extensive use of CSP will generally become optimal after 2050. Constraints on the use of nuclear and/or of IGCC coal with CCS have an impact on the size of investments in 2050, but a smaller effect on later years, when the cost of CSP declines sharply. CSP generation by MENA is optimal from 2040 onwards and large, under all climate policy scenarios. In the second part of the century it becomes optimal even in the Business-as-Usual scenario. (ii) In the first part of the century, it is convenient for Europe to import electricity from the MENA region only when there are constraints to the expansion of nuclear and/or to the use of IGCC coal with CCS. Trade starts around 2040, at about 30c\$/KWh. The price of CSP decreases over time to $10-11 \mathrm{c} \$ / \mathrm{KWh}$. In the second part of the century (iii) CSP covers a very large share of the electricity mix in all regions in which the option is available. CSP is an important technology option that (iv) has a high stabilization cost option value, especially in coal-intensive countries. Depending on the scenarios, the option value, measured as the percentage of discounted GDP, ranges between 2.1 and 4.1\% of GDP in MENA, between 1.1 and $3.4 \%$ in China, between 0.2 and $1.2 \%$ in the USA, between 0.1 and $1.3 \%$ in E-EU and between 0.1 and $0.4 \%$ in W-EU. Most importantly, CSP reduces greatly the option value of nuclear power and IGCC coal with CCS. If we compare our results with the literature $(v)$ we find it optimal to invest later than most studies do. We also find that it is optimal to invest less in CSP if we do not constrain nuclear and/or IGCC coal with CCS. The constrained scenarios increase the expansion of CSP and anticipate it. Trade between Europe and MENA also occurs later than what suggested in the non-peer reviewed literature. However, the model is flexible and the expansion of CSP in the long-term is very large. Our scenarios might be optimistic in the long run because they do not take into account the difficulties that can arise from a large surface area occupied by CSP plants and by a large number of grid connections, especially across the Mediterranean.

\footnotetext{
${ }^{25}$ http://www.desertec.org/en/concept/questions-answers/\#c809, accessed on June 8, 2011.
} 
Earlier investments in CSP could be motivated by some external benefits beyond the reduction of $\mathrm{CO}_{2}$ emissions. This study examines if learning externalities motivate subsidies and government support to CSP projects already in the next decade. Results reveal that a moderate subsidy or a command-andcontrol policy (beyond the pricing of the environmental externality), might increase welfare. Investments should occur about five years earlier, still much later than what foreseen in many influential reports.

Finally, the literature on CSP and the political debate have largely neglected the complexities of building the institutions capable of managing a large Mediterranean market for electricity. Without a sound institutional framework, tensions might emerge and jeopardize the overall deployment of CSP power in the Mediterranean region. In particular, high attention should be devoted to set up the mechanisms and rules that will determine the price of electricity. This study shows that there are incentives that may lead MENA countries to form a cartel. The emergence of market power can be troublesome for Europe. Equally problematic, in the case of a large deployment of CSP, might be the large exposure of the European power network to foreign shocks. Instead of increasing energy security, a massive use of imported CSP might increase energy dependency.

Therefore our prospects for CSP penetration in Europe may be optimistic.. Very large is instead the potential of CSP in China, the USA, and in MENA countries, where the only constraints are technological.

This study supports the following policy recommendations, with all the caveats discussed in the paper. ( $i)$ It is too early to subsidize large scale development plans of CSP, as subsidies might lead to an inefficient mitigation portfolio. (ii) However, from now until 2030-2035 governments have a role to play in fostering the development of a limited number of pilot power plants, especially in specific types of areas, such as deserts, to gain more information on the technological challenges that CSP might have in the mediumterm and to promote cost reductions. HVDC cables should also be tested in deserts, where temperatures are high and sand storms might cause disruptions. Tower CSP plants should also be tested to understand the effective heat storage capacity. (iii) A Mediterranean "Super-Grid" might not be necessary if nuclear power and IGCC coal with CCS are feasible technology options. If, instead, there are limits to the deployment of these technologies, CSP in Northern Africa might play an important role after 2040 in a moderate stabilization policy scenario (stabilization of GHG concentration at $535 \mathrm{ppm}$-eq in 2100). If the technology proves to be reliable, European and Northern African countries should start building the institutions to manage a Mediterranean trade of electricity around 2025. 


\section{References}

Arce, P., Medrano, M., Gil, A., Oró, E., Cabeza, L.F., 2011. Overview of thermal energy storage (TES) potential energy savings and climate change mitigation in Spain and Europe. Applied Energy, 88(8), 2764-2774.

Arvizu, D., Balaya, P., Cabeza, L., Hollands, T., Jäger Waldau, A., Kondo, M., Konseibo, C., Meleshko, V., Stein, W., Tamaura, Y., Xu, H., Zilles, R., 2011. Direct Solar Energy, in: Edenhofer, O., Pichs Madruga, R., Sokona, Y., Seyboth, K., Matschoss, P., Kadner, S., Zwickel, T., Eickemeier, P., Hansen, G., Schlömer, S., von Stechow, C. (Eds.), IPCC Special Report on Renewable Energy Sources and Climate Change Mitigation. Cambridge University Press, Cambridge, United Kingdom and New York, NY, USA.

Bauer, N., Edenhofer, O. , Jakob, M., Ludig, S., Lüken, M., 2008. Electricity Trade among World Regions. Trade Theoretic Foundation of Energy-Economy Models, Potsdam-Institute for Climate Impact Research (PIK), Germany, November 142008.

Bosetti, V., Carraro, C., Galeotti, M., Massetti, E., Tavoni M., 2006. WITCH: A World Induced Technical Change Hybrid Model. The Energy Journal, Special Issue on Hybrid Modeling of EnergyEnvironment Policies: Reconciling Bottom-up and Top-down, pp.13-38.

Bosetti, V., Massetti, E., Tavoni, M., 2007a. The WITCH model: Structure, Baseline and Solutions, FEEM Working Paper 10-2007, Milan.

Bosetti, V., Carraro, C., Galeotti, M., Massetti, E., Tavoni M., 2007b. Optimal Energy Investment and R\&D Strategies to Stabilise Greenhouse Gas Atmospheric Concentrations, FEEM Working Paper 952007, Milan.

Bosetti, V., Carraro, C., M., Massetti, E., Sgobbi, A., Tavoni M., 2009. Optimal Energy Investment and R\&D Strategies to Stabilise Greenhouse Gas Atmospheric Concentrations. Resource and Energy Economics 31-2, pp.123-137.

Bosetti, V., Catenacci, M., Fiorese, G., Verdolini, E., 2012. The Future Prospect of PV and CSP solar technologies: An Expert Elicitation Survey. Energy Policy, http://dx.doi.org/10.1016/j.enpol.2012.06.024

Breyer, C., Knies, G., 2009. Global Energy Supply Potential of Concentrating Solar Power, Proceedings SolarPaces 2009, Berlin.

Bruckner, T., Chum, H., Jäger Waldau, A., Killingtveit, Å., Gutiérrez Negrín, L., Nyboer, J., Musial, W., Verbruggen, A., Wiser, R., 2011. Annex III: Cost Table, in: Edenhofer, O., Pichs Madruga, R., Sokona, Y., Seyboth, K., Matschoss, P., Kadner, S., Zwickel, T., Eickemeier, P., Hansen, G., Schlömer, S., von Stechow, C. (Eds.), IPCC Special Report on Renewable Energy Sources and Climate Change Mitigation. Cambridge University Press, Cambridge, United Kingdom and New York, NY, USA.

Chien, J.C., 2009. Concentrating Solar Thermal Power: A Viable Alternative in China's Energy Supply, Master Thesis, Lauder Institute of International Studies.

Coase, R. H., 1960. The Problem of Social Cost. Journal of Law and Economics 3 (1): 1-44.

Czisch, G., 2004. Least-cost European/Transeuropean electricity supply entirely with renewable Energies, unpublished paper.

Deutch, J., Moniz, E.J., Ansolabehere, S., Driscoll, M., Gray, P.E., Holdren, J.P., Joskow, P.L., Lester, R.K., Todreas, N.E., Beckjord, E.S., 2003. The future of nuclear power: an interdisciplinary MIT study, Massachusetts Institute of Technology, Boston, MA.

ECF, 2010. Roadmap 2050. A practical guide to a prosperous low carbon Europe, European Climate Foundation.

Enermodal Engineering Limited, 1999. Cost reduction study for solar thermal power plants. Prepared for The World Bank.

IEA, 2003. Renewables for Power Generation. Status \& Prospects, International Energy Agency, Paris, France.

IEA, 2008. Energy Technologies Perspectives 2008, International Energy Agency, Paris, France. 
IEA, 2010a. Energy Technology Perspectives 2010, International Energy Agency, Paris, France.

IEA, 2010b. Technology Roadmap: Concentrating Solar Power, International Energy Agency, Paris, France.

IEA, 2010c. World Energy Outlook 2010, International Energy Agency, Paris, France.

Jacobson, M.Z., Delucchi, M.A., 2010. Providing all global energy with wind, water, and solar power, Part I: Technologies, energy resources, quantities and areas of infrastructure, and materials. Energy Policy 2010-11-040.

Kaltschmitt, M., Streicher, W., Wiese, A., 2007. Renewable Energy, Springer.

Kearney, D., 2003. Concentrating Solar Power Systems, National Center for Photovoltaics and Solar Program Review Meeting Proceedings, 24-26 March 2003, Denver, Colorado (CD-ROM). NREL/CD520-33586. Golden, Colorado, National Renewable Energy Laboratory.

Krey, V., Clarke, L., 2011. Role of renewable energy in climate mitigation: a synthesis of recent scenarios. Climate Policy, 11: 1131-1158.

Joskow, P.L., 2012. “Creating a Smarter U.S. Electricity Grid.” Journal of Economic Perspectives, 26(1): $29-48$.

Lubowski, R.N., Vesterby, M., Bucholtz, M., Baez, A., 2006. Major Uses of Land in the United States, 2002. United States Department of Agriculture, Economic Research Service, Economic Information Bulletin No. (EIB-14), May 2006.

May, N., 2005. Eco-balance of Solar Electricity Transmission from North Africa to Europe, Diploma Thesis, Technical University of Braunschweig.

Meyer, A., 2000. Contraction and convergence. The global solution to climate change, Foxhole, Devon, UK: Green Books for the Schumaker Sociey.

Neij, L., 2008. Cost development of future technologies for power generation - A study based on experience curves and complementary bottom-up assessments. Energy Policy 36, pp.2200-2211.

Patt, A., Battaglini, A., Komendantova, N., Lilliestam, J., 2008. Linking North Africa's Renewable Energy Resources to Europe: policy challenges, Background paper for a scientific workshop International Institute for Applied Systems Analysis, Laxenburg, Austria, 24 - 26 November 2008.

Richter, C., Teske, S., Nebrera, J. A., 2009. Concentrating Solar Power Global Outlook 09, Greenpeace International / European Solar Thermal Electricity Association (ESTELA) / IEA SolarPACES, Report 2009.

Streater, S., 2010. 1,000-Megawatt Plant in Calif. Marks New Milestone in Solar Expansion, The New York Times (26-8-2010).

Trieb, F., 2006. Trans-Mediterranean Interconnection for Concentrationg Solar Power, German Aerospace Center (DLR).

Trieb, F., Müller-Steinhagen, H., 2007. The DESERTEC concept, in: Knies G., Möller, U., Straub, M. (Eds.), Clean power from the deserts: The DESERTEC concept for energy, water and climate security, White Paper, 23-44. Hamburg: TREC, 2007.

http://www.desertec.org/downloads/articles/trec_white_paper.pdf Accessed 25 August 2008.

Trieb, F., 2009a. Combined Solar Power and Desalination Plants: Techno-Economic Potential in Mediterranean Partner Countries, German Aerospace Center (DLR).

Trieb, F., 2009b. Global Potential of Concentrating Solar Power, Proceedings SolarPaces 2009, Berlin.

Trieb, F., Müller-Steinhagen, H., Kern, J., 2011. Financing concentrating solar power in the Middle East and North Africa-Subsidy or investment? Energy Policy 39: 307-317.

Ummel, K., Wheeler, D., 2008. Desert Power: The Economics of Solar Thermal Electricity for Europe, North Africa, and the Middle East, Center for Global Development Working Paper Number 156.

US DOE, 2008. Solar Energy Technologies Programme, Multi Year Program Plan 2008 -2012. U.S. Department of Energy (US DOE), Washington, DC, USA. 
Williges, K, Lilliestam, J., Patt, A., 2010. Making concentrated solar power competitive with coal: The costs of a European feed-in tariff. Energy policy 38(6):3089-97. 


\section{Appendix - List of Main Equations}

In this Appendix we reproduce the main equations of the model. For a full description of the model please refer to Bosetti et al. (2007a, 2009). The website www.witchmodel.org contains useful information on the model. The list of variables is reported at the end of this Section.

In each region, indexed by $n$, a social planner maximises the following utility function:

$W(n)=\sum_{t} U[C(n, t), L(n, t)] R(t)=\sum_{t} L(n, t)\{\log [c(n, t)]\} R(t)$,

where $t$ are 5 -year time spans and the pure time preference discount factor is given by:

$$
R(t)=\prod_{v=0}^{t}[1+\rho(v)]^{-t},
$$

where the pure rate of time preference $\rho_{\rho}(v)$ is assumed to decline over time. Moreover, $c(n, t)=\frac{C(n, t)}{L(n, t)}$ is per capita consumption.

Output gross of climate change damages, in the non-oil sector, is produced by combining a capital-labour intermediate input with energy services $(E S)$ in a constant elasticity of substitution (CES) production function:

$$
G Y(n, t)=\operatorname{TFP}(n, t)\left[\alpha_{Y}(n)\left(K(n, t)^{\beta} L(n, t)^{1-\beta}\right)^{\rho_{Y}}+\left(1-\alpha_{Y}(n)\right) E S(n, t)^{\rho_{Y}}\right]^{1 / \rho_{Y}} .
$$

Total factor productivity $\operatorname{TFP}_{(n, t)}$ evolves exogenously with time. The labour force is set equal to population $(L)$, which evolves exogenously. Capital $(K)$ evolves following a standard pattern:

$$
K(n, t+1)=K(n, t)\left(1-\delta_{G Y}\right)+I(n, t)
$$

Energy services are an aggregate of energy $(E N)$ and a stock of knowledge combined with a CES function:

$$
E S(n, t)=\left[\alpha_{H E}(n) H E(n, t)^{\rho_{E S}}+\alpha_{E N}(n) E N(n, t)^{\rho_{E S}}\right]^{1 / \rho_{E S}} .
$$

New ideas which contribute to the stock of energy knowledge, $Z_{H E}(n, t)$, are produced using R\&D investments, $I_{R \& D}(n, t)$, together with the previously cumulated knowledge stock $H E(n, t)$ :

$$
Z_{H E}(n, t)=a I_{H E}(n, t)^{b} H E(n, t)^{c} H K L(n, t)^{d} .
$$

The knowledge stock evolves as follows:

$$
H E(n, t+1)=H E(n, t)(1-\delta)+Z_{H E}(n, t)
$$

\section{The Energy Sector}

Energy is a combination of electric $(E L)$ and non-electric energy $(N E L)$ :

$$
E N(n, t)=\left[\alpha_{E L}(n) E L(n, t)^{\rho_{E N}}+\alpha_{N E L}(n) N E L(n, t)^{\rho_{E N}}\right]^{1 / \rho_{E N}} .
$$

Each factor is further decomposed into several sub-components that are aggregated using CES, linear and Leontief production functions. In particular:

$$
\begin{aligned}
& E L(n, t)=\left[E L_{2}(n, t)+\alpha_{H Y D R O}(n) E L_{H Y D R O}(n, t)\right] ; \\
& E L_{2}(n, t)=\left[\alpha_{F F}(n) F F(n, t)^{\rho_{E L 2}}+\alpha_{N U K E}(n) E L_{N U K E}(n, t)^{\rho_{E L 2}}+\alpha_{W \& S}(n) E L_{W \& S}(n, t)^{\rho_{E L 2}}\right]^{1 / \rho_{E L 2}} ;
\end{aligned}
$$




$$
\begin{aligned}
& F F(n, t)=\left[\alpha_{C O A L}(n) E L_{C O A L}(n, t)^{\rho_{F F}}+\alpha_{O I L}(n) E L_{O I L}(n, t)^{\rho_{F F}}+\alpha_{G A S}(n) E L_{G A S}(n, t)^{\rho_{F F}}\right]^{1 / \rho_{F F}} ; \\
& E L_{C O A L}(n, t)=\left[\alpha_{P C}(n) E L_{P C}(n, t)^{\rho_{E L_{\text {Oou }}}}+\alpha_{I G C C}(n) E L_{I G C C}(n, t)^{\rho_{E L_{\text {Lou }}}}\right]^{1 / \rho_{E_{L I O A N}}} .
\end{aligned}
$$

\section{The Super-Grid}

We reproduce here the equations that have been illustrated in the main text of the paper for an easy reference:

$$
\begin{aligned}
& E L_{C S P, T}(n, t)=E L_{C S P}(n, t)+E L_{C S P, X}(n, t) . \\
& E L_{C S P}(n, t)=\min \left\{\mu_{C S P, n} K_{C S P}(n, t) ; \theta_{C S P} O \& M_{C S P}(n, t) ; \mu_{\text {grid }, n} K_{\text {grid }}(n, t) ; \theta_{\text {grid }} O \& M_{\text {grid }}(n, t)\right\} . \\
& E L_{C S P, X}(n, t)=\min \left\{\mu_{n, C S P} K_{C S P}(n, t) ; \theta_{C S P} O \& M_{C S P}(n, t) ; \mu_{n, X} K_{\text {grid }, X}(n, t) ; \theta_{\text {grid }} O \& M_{\text {grid }, X}(n, t)\right\} . \\
& \sum_{n} E L_{C S P, X}(n, t)=0 \quad \forall t \\
& K_{C S P}(n, t+1)=K_{C S P}(n, t)\left(1-\delta_{C S P}\right)+\frac{I_{C S P}(n, t)}{S C_{C S P}(n, t)} . \\
& K_{\text {grid }}(n, t+1)=K_{\text {grid }}(n, t)\left(1-\delta_{\text {grid }}\right)+\frac{I_{\text {grid }}(n, t)}{S C_{\text {grid }}(n, t)} . \\
& K_{\text {grid }, X}(n, t+1)=K_{\text {grid }, X}(n, t)\left(1-\delta_{\text {grid }}\right)+\frac{I_{\text {grid, }, X}(n, t)}{S C_{\text {grid }}(n, t)} . \\
& K_{\text {grid }, T}(n, t)=K_{\text {grid }}(n, t)+K_{\text {grid }, X}(n, t) .
\end{aligned}
$$

$S C_{C S P}(n, t+1)=S C_{C S P}\left(n, t_{0}\right) \cdot{\frac{T K(t)}{T K\left(t_{0}\right)}}^{-(\alpha)} \cdot\left(1+\left(\frac{\left(\frac{I_{C S P}(n, t+1)}{S C_{C S P}(n, t+1)}\right)}{\beta}\right)^{\gamma}\right)$

$T K(t+1)=T K(t)+\sum_{n} \frac{I_{C S P}(n, t)}{S C_{C S P}(n, t)}$.

$$
O \& M_{\text {grid }, T}(n, t)=O \& M_{\text {grid }}(n, t)+O \& M_{\text {grid }, X}(n, t) .
$$

$$
\begin{aligned}
C(n, t)= & Y(n, t)-I_{c}(n, t)-\sum_{j} I_{R \& D, j}(n, t)-\sum_{j} I_{j}(n, t)-\sum_{j} O \& M_{j}(n, t)-I_{C S P}(n, t)-I_{\text {grid }, T}(n, t) . \\
& -O \& M_{C S P}(n, t)-O \& M_{g r i d, T}(n, t),
\end{aligned}
$$

$F F(n, t)=\left[\begin{array}{l}\alpha_{C O A L}(n) E L_{C O A L}(n, t)^{\rho_{F F}}+\alpha_{O I L}(n)\left(E L_{O I L}(n, t)+E L_{C S P, o i l}(n, t)\right)^{\rho_{F F}}+ \\ +\alpha_{G A S}(n)\left(E L_{G A S}(n, t)+E L_{C S P, g a s}(n, t)\right)^{\rho_{F F}}\end{array}\right]^{1 / \rho_{F F}}$

$E L_{\text {NUKE }}(n, t)=\left[E L_{\text {NUCLEAR }}(n, t)+E L_{\text {BACKSTOP }}(n, t)+E L_{C S P, \text { nuke }}(n, t)\right] ;$ 


$$
\begin{aligned}
& E L_{C O A L}(n, t)=\left[E L_{P C}(n, t)+E L_{I G C C}(n, t)+E L_{C S P, c c s}(n, t)\right] . \\
& Y(n, t)=G Y(n, t)-\sum_{f} P_{f}(n, t) * X_{f, e x t r}(n, t)-\sum_{f} P_{f_{\text {int }}}(n, t) * X_{f, n e t i m p}(n, t) \\
& \quad-P_{C S S}(n, t) * C C S(n, t)-E L_{C S P, X}(n, t) P_{C S P}(t)
\end{aligned}
$$

\section{Climate Module}

Carbon dioxide emissions from combustion of fossil fuels $\left(x_{f}\right)$ are derived applying stoichiometric coefficients to the total amount of fossil fuels utilised. Emissions associated to non-conventional oil production are also tracked. By using carbon capture and sequestration $(C C S)$ it is possible to reduce the amount of $\mathrm{CO}_{2}$ emissions in the atmosphere:

$$
\mathrm{CO}_{2}(n, t)=\sum_{f} \omega_{f, \mathrm{CO}_{2}} X_{f}(n, t)+\sum_{g} \phi_{g, C O_{2}} \operatorname{OIL}_{p r o d}(n, t, g)-\operatorname{CCS}(n, t) .
$$

For details on land use emissions and on non- $\mathrm{CO}_{2}$ gases please see Bosetti et al. (2009).

Temperature increases through augmented radiating forcing $F$, moderated by the cooling effect of $\mathrm{SO}_{2}$ aerosols, $\operatorname{cool}(t+1)$ :

$$
T(t+1)=T(t)+\sigma_{1}\left\{F(t+1)-\lambda T(t)-\sigma_{2}\left[T(t)-T_{L O}\right]\right\}-\operatorname{cool}(t+1) .
$$

\section{List of Variables}

$\delta_{i}=$ Depreciation rate

$\mu_{C S P, n}=$ Full load hours for a CSP power plant in region $n$

$\mu_{\text {grid, },}=$ Full load hours for the domestic Super-Grid in region $n$

$C=$ Consumption

$c=$ Per-capita consumption

$C C S=\mathrm{CO}_{2}$ captured and sequestered

$\mathrm{CO}_{2}=$ Emissions from combustion of fossil fuels

$\Delta=$ Additional oil capacity

$E L=$ Electric energy

$E L_{i}=$ Electric energy use from the $i^{\text {th }}$ generation technology

$E L_{C S P, T}=$ Total electric energy produced with CSP

$E L_{C S P}=$ Electric energy produced with CSP for domestic consumption

$E L_{C S P, X}=$ Electric energy produced with CSP for export

$E N=$ Energy

$E S=$ Energy services

$F=$ Radiative forcing

$H E=$ Energy knowledge

$I_{C S P}=$ Investments in CSP plants

$I_{\text {grid, },}=$ Investments in the whole Super-Grid infrastructure

$I_{\text {grid }}=$ Investments in Super-Grid for domestic consumption

$I_{\text {grid }, X}=$ Investments in Super-Grid for export

$I_{R \& D}=$ Investment in energy R\&D

$I=$ Investment in the final good sector

$L=$ Population

$K=$ Stock of capital in the final good sector

$K_{C S P}=$ Stock of capital in CSP

$T K_{C S P}=$ World cumulative built capacity in CSP (no depreciation)

$K_{\text {grid }, T}=$ Stock of capital in the whole Super-Grid infrastructure

$K_{\text {grid }}=$ Stock of capital in the Super-Grid infrastructure for domestic consumption

$K_{\text {grid }, X}=$ Stock of capital in the Super-Grid infrastructure for export 
$N E L=$ Non-electric energy

$N I P=$ Net import of carbon permits

$O \& M_{C S P}=$ Operation and maintenance costs associated with CSP generation

$O \& M_{\text {grid }, T}=$ Operation and maintenance costs associated with the whole Super-Grid

$O \& M_{\text {grid }}=$ Operation and maintenance costs associated with Super-Grid for domestic consumption

$O \& M_{\text {grid }, X}=$ Operation and maintenance costs associated with Super-Grid for export

$P_{C S P}=$ Price of the traded CSP power

$\mathrm{p}=$ Price of carbon permits

$P_{Z}=$ a vector of prices for the input vector $X_{Z}$

$R=$ Discount factor

$\mathrm{SC}_{C S P}=$ Investment costs for the construction of CSP plants

$\mathrm{SC}_{\text {grid }}=$ Investment costs for the construction of the Super-Grid

$T=$ Temperature level

TFP $=$ Total factor productivity

$U=$ Instantaneous utility

$W=$ Welfare

$X_{Z}=$ a vector including inputs that are considered a net loss for the economy

$Y=$ Gross Domestic Product

$Z_{H E}=$ Flow of new energy knowledge

\section{Assigned Values to Key Parameters:}

[Table A1 about here]

$\delta_{\mathrm{CSP}}=0.1$

$\delta_{\text {grid }}=0.1$

$\alpha=0.15$

$\beta=380$

$\gamma=3$ 


\section{Online Appendix}

In this online Appendix we test the robustness of our results by varying the values of the key input parameters. We focus on the assumptions for CSP electricity generation, long-distance transmission through a Super-Grid and its trade. We test the alternative assumptions using as a reference case the unconstrained stabilization scenario. More in detail, we test variations ceteris paribus of $\pm 5 \%, \pm 10 \%$, $\pm 20 \%$ and $\pm 30 \%$ of the reference value of: (i) initial CSP investments costs $\left(S C_{C S P}\right)$; (ii) SG infrastructure investments costs $\left(S C_{\text {grid }}\right)$; and (iii-v) the parameters of the cost function, related to the learning by doing effect $(\alpha)$ and to the cost increase due to limited supply of intermediate goods $(\beta, \gamma)$.

[Figure A1 about here]

[Figure A2 about here]

[Figure A3 about here]

Figure A1-A3 depict the changes of: (i) future investment costs, (ii) trade of CSP Electricity between MENA and Europe, and (iii) world CSP installed capacity, for the alternative assumptions on the above parameters. Further results are available upon request from the authors. For simplicity, in the graphs we report the values of the variables for variations of $0 \%, \pm 5 \%, \pm 30 \%$. We find that all three output variables are more sensitive to the initial value of the CSP investment cost and to the progress ratio used in the learning by doing term of the cost function, compared to the other three. For small input parameters variations (5-10\%), output results are stable; for larger variations results differ sensibly, though in all cases the differences are mainly quantitative and not qualitative.

The timing of CSP deployment for MENA is influenced by variations only in CSP investment costs, while for the USA and China also by the progress ratio. The optimal timing for the Europe-MENA trade is mainly sensitive to the previous two parameters; Super-Grid investment costs are also influential but to a smaller extent.

To conclude, the sensitivity analysis shows that the crucial parameters for this analysis are the initial investment costs for the CSP power plants and the rate at which these will decrease as cumulative installed capacity grows, therefore particular care should be devoted to their estimation.

[Table A1 about here]

[Table A2 about here] 


\section{List of Tables}

Technological parameters

\begin{tabular}{|c|c|c|c|c|c|c|c|c|}
\hline Region & Production Location & $\begin{array}{c}\text { DNI } \\
\left(\mathrm{kWh} / \mathrm{m}^{2} \mathrm{y}^{-1}\right)\end{array}$ & $\begin{array}{l}\text { Full load } \\
\text { hours } \\
\text { (h) }\end{array}$ & $\begin{array}{c}\text { Invest cost } \\
\text { CSP } \\
(\mathrm{US} \$ / \mathrm{kW})\end{array}$ & $\begin{array}{c}\mathrm{O} \& \mathrm{M}_{\mathrm{CSP}} \\
(\mathrm{US} \$ / \mathrm{kW})\end{array}$ & $\begin{array}{l}\text { SG lenght } \\
(\mathrm{km})\end{array}$ & $\begin{array}{c}\text { Invest. Cost } \\
\text { SG } \\
(\mathrm{US} \$ / \mathrm{kW})\end{array}$ & $\begin{array}{c}\mathrm{O} \& \mathrm{M}_{\mathrm{SG}} \\
(\mathrm{US} \$ / \mathrm{kW})\end{array}$ \\
\hline China & Tibet (Xigaze) & 2300 & 4110 & 6500 & 127.5 & 2800 & 329 & 6.6 \\
\hline MENA & Sahara desert & 2190 & 3680 & 6500 & 127.5 & 3000 & 336 & 6.7 \\
\hline USA & Arizona (Phoenix) & 2600 & 4600 & 6500 & 127.5 & 577 and 3447 & 277 & 5.5 \\
\hline
\end{tabular}

Cost of electricity

\begin{tabular}{|c|c|c|c|c|c|c|c|}
\hline \multirow[t]{2}{*}{ Region } & \multicolumn{3}{|c|}{$\begin{array}{l}\text { Cost of electricity (US\$ cents/kWh) } \\
\text { standard interest rates }\end{array}$} & \multicolumn{2}{|c|}{ Interest rates in WITCH } & \multicolumn{2}{|c|}{$\begin{array}{r}\text { Cost of electricity } \\
\text { (US\$ cents/kWh) } \\
\text { model's interest rates }\end{array}$} \\
\hline & $3 \%$ & $7 \%$ & $10 \%$ & 2010 & 2050 & 2010 & 2050 \\
\hline China & 21.6 & 28.2 & 33.2 & $11.8 \%$ & $4.9 \%$ & 36.3 & 24.8 \\
\hline MENA & 23.0 & 30.0 & 35.3 & $5.9 \%$ & $5.0 \%$ & 28.0 & 26.5 \\
\hline USA & 19.2 & 25.0 & 29.5 & $4.0 \%$ & $2.5 \%$ & 20.6 & 18.4 \\
\hline SSREN & $11.0-19.0$ & $16.0-25.0$ & $20.0-31.0$ & & & & \\
\hline
\end{tabular}

Table 1. Technological parameters and cost of electricity.

\begin{tabular}{lcccc}
\hline Scenario name & \multicolumn{2}{l}{$\begin{array}{l}\text { Stabilization of GHG } \\
\text { in 2100 }\end{array}$} & $\begin{array}{c}\text { Nuclear power blocked } \\
\text { at 2005 level }\end{array}$ & $\begin{array}{c}\text { CCS is not available early } \\
\text { investments in CSP }\end{array}$ \\
\hline BaU & -- & NO & NO & NO \\
NC-BaU & -- & YES & NO & NO \\
CC-BaU & -- & NO & YES & NO \\
NCC-BaU & -- & YES & YES & NO \\
U-Stab & & NO & NO & NO \\
NC-Stab & 535 ppme & YES & YES & NO \\
CC-Stab & 535 ppme & NO & YES & NO \\
NCC-Stab & 535 ppme & YES & NO & YES \\
Anticipated-U-Stab & 535 ppme & NO & & \\
\hline
\end{tabular}

\section{Table 2. Simulation scenarios.}

MENA - CSP Export Market Size

Bau U-Stab NC-Stab CC-Stab NCC-Stab

Annual Revenue (Billion \$)

$\begin{array}{cccccc}2040 & - & - & - & - & 2 \\ 2055 & - & - & 111 & 87 & 218 \\ 2070 & - & 95 & 254 & 129 & 291 \\ 2085 & - & 135 & 324 & 154 & 340 \\ 2100 & - & 155 & 368 & 168 & 375\end{array}$

CSP GDP (\% of total GDP)

$\begin{array}{cccccc}2040 & - & - & - & - & 0.03 \% \\ 2055 & - & - & 1.39 \% & 1.10 \% & 2.69 \% \\ 2070 & - & 0.81 \% & 2.14 \% & 1.10 \% & 2.45 \% \\ 2085 & - & 0.84 \% & 1.99 \% & 0.95 \% & 2.09 \% \\ 2100 & - & 0.75 \% & 1.76 \% & 0.81 \% & 1.80 \%\end{array}$

Europe - CSP Annual Expenditure

Bau U-Stab NC-Stab CC-Stab NCC-Stab

Western Europe (\% of total GDP)

$\begin{array}{cccccc}2040 & - & - & - & - & - \\ 2055 & - & - & 0.28 \% & 0.20 \% & 0.54 \% \\ 2070 & - & 0.19 \% & 0.54 \% & 0.25 \% & 0.61 \% \\ 2085 & - & 0.23 \% & 0.60 \% & 0.26 \% & 0.62 \% \\ 2100 & - & 0.24 \% & 0.60 \% & 0.26 \% & 0.62 \%\end{array}$

Eastern Europe (\% of total GDP)

$\begin{array}{cccccc}2040 & - & - & - & - & 0.07 \% \\ 2055 & - & - & 0.67 \% & 0.78 \% & 1.57 \% \\ 2070 & - & 0.61 \% & 1.34 \% & 0.88 \% & 1.60 \% \\ 2085 & - & 0.75 \% & 1.45 \% & 0.86 \% & 1.54 \% \\ 2100 & - & 0.75 \% & 1.44 \% & 0.81 \% & 1.48 \%\end{array}$


Table 3. MENA CSP Export Market Size and European expenditure relative to regional GDP.

\begin{tabular}{|c|c|c|c|c|c|c|c|c|}
\hline & \multicolumn{4}{|c|}{ without CSP } & \multicolumn{4}{|c|}{ with CSP } \\
\hline & $\mathrm{U}$ & $\mathrm{NC}$ & $\mathrm{CC}$ & $\mathrm{NCC}$ & $\mathrm{U}$ & $\mathrm{NC}$ & $\mathrm{CC}$ & $\mathrm{NCC}$ \\
\hline CHINA & $4.3 \%$ & $5.3 \%$ & $5.4 \%$ & $7.2 \%$ & $3.2 \%$ & $3.3 \%$ & $3.6 \%$ & $3.8 \%$ \\
\hline E-EU & $2.7 \%$ & $3.5 \%$ & $3.2 \%$ & $4.8 \%$ & $2.5 \%$ & $2.9 \%$ & $2.9 \%$ & $3.5 \%$ \\
\hline MENA & $4.8 \%$ & $5.1 \%$ & $5.5 \%$ & $6.2 \%$ & $2.7 \%$ & $2.4 \%$ & $2.7 \%$ & $2.1 \%$ \\
\hline USA & $1.8 \%$ & $2.4 \%$ & $2.2 \%$ & $3.2 \%$ & $1.6 \%$ & $1.7 \%$ & $1.8 \%$ & $2.0 \%$ \\
\hline W-EU & $0.8 \%$ & $1.0 \%$ & $0.9 \%$ & $1.4 \%$ & $0.8 \%$ & $0.9 \%$ & $0.9 \%$ & $1.0 \%$ \\
\hline
\end{tabular}

Stabilization cost option value (\% GDP losses, discounted at 5\%)

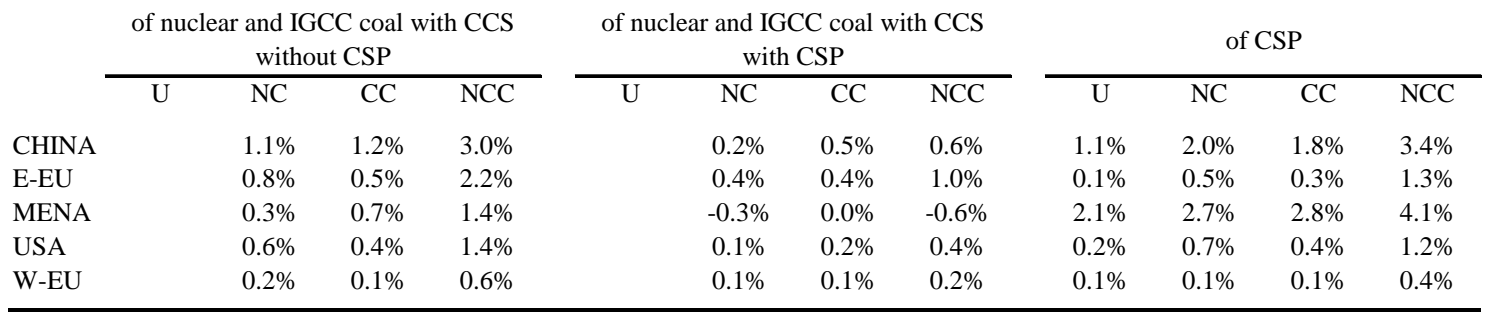

Table 4. The option value of CSP. 


\begin{tabular}{|c|c|c|c|c|c|c|c|c|}
\hline \multirow[t]{2}{*}{ Policy } & \multicolumn{3}{|c|}{ Electricity (TWh) } & \multicolumn{3}{|c|}{ Capacity (GW) } & \multicolumn{2}{|c|}{ Europe-MENA trade } \\
\hline & 2020 & 2030 & 2050 & 2020 & 2030 & 2050 & $\begin{array}{c}\text { starts in } \\
\text { year }\end{array}$ & $\begin{array}{c}\text { TWh } \\
(2050)\end{array}$ \\
\hline \multicolumn{9}{|l|}{ This study } \\
\hline $\mathrm{BaU}$ & 0 & 0 & 0 & 0 & 0 & 0 & never & 0 \\
\hline U-Stab & 0 & 0 & 1195 & 0 & 0 & 312 & 2060 & 0 \\
\hline NC-Stab & 0 & 0 & 4251 & 0 & 0 & 1020 & 2050 & 129 \\
\hline CC-Stab & 0 & 0 & 6065 & 0 & 0 & 1475 & 2045 & 401 \\
\hline NCC-Stab & 0 & 0 & 10300 & 0 & 0 & 2483 & 2045 & 1257 \\
\hline U-Stab-Early & & & & & & & 2055 & \\
\hline \multicolumn{9}{|c|}{ Krey and Clarke (2011) - Median values of 57 IAM scenarios } \\
\hline $\mathrm{BaU}$ & 35 & 278 & 2083 & n.a. & n.a. & n.a. & n.a. & n.a. \\
\hline $440-660 \mathrm{ppm}$ & 139 & 361 & 2722 & n.a. & n.a. & n.a. & n.a. & n.a. \\
\hline$<440 \mathrm{ppm}$ & 208 & 694 & 4167 & n.a. & n.a. & n.a. & n.a. & n.a. \\
\hline \multicolumn{9}{|l|}{ Bauer et al. (2008) } \\
\hline $\mathrm{BaU}$ & n.a. & n.a. & n.a. & n.a. & n.a. & n.a. & never & 0 \\
\hline $2^{\circ} \mathrm{C}$ & n.a. & n.a. & n.a. & n.a. & n.a. & n.a. & 2055 & 3514 \\
\hline \multicolumn{9}{|c|}{ Greenpeace - SolarPACES - ESTELA (Richeter 2009) } \\
\hline Reference & 22 & 40 & 66 & 7 & 13 & 18 & n.a. & $>560$ \\
\hline Moderate & 246 & 871 & 3638 & 69 & 231 & 831 & n.a. & $>560$ \\
\hline Advanced & 365 & 1499 & 7878 & 84 & 342 & 1524 & n.a. & $>560$ \\
\hline \multicolumn{9}{|c|}{ German Aerospace Center (MENA and Europe - Med-CSP; Trieb 2006) } \\
\hline $\begin{array}{l}-30 \% \text { global } \\
\text { emissions in } 2050\end{array}$ & n.a. & n.a. & n.a. & n.a. & n.a. & n.a. & 2020 & 708 \\
\hline \multicolumn{9}{|c|}{ ETP Blue Map Scenario (IEA 2008) } \\
\hline $\begin{array}{l}-50 \% \text { global } \\
\text { emissions in } 2050\end{array}$ & n.a. & n.a. & 2200 & n.a. & n.a. & 630 & n.a. & n.a. \\
\hline \multicolumn{9}{|c|}{ IEA Global CSP Outlook 2011} \\
\hline $\begin{array}{l}-50 \% \text { global } \\
\text { emissions in } 2050\end{array}$ & 414 & 1140 & 4770 & 148 & 337 & 1089 & $2020-2030$ & n.a. \\
\hline \multicolumn{9}{|l|}{ WEO 2010 (IEA 2010c) } \\
\hline Current Policies & 37 & 110 & n.a. & 12 & 31 & n.a. & n.a. & n.a. \\
\hline 450 ppme & 144 & 519 & n.a. & 41 & 141 & n.a. & n.a. & n.a. \\
\hline
\end{tabular}

Table 5. Comparison with the literature. 


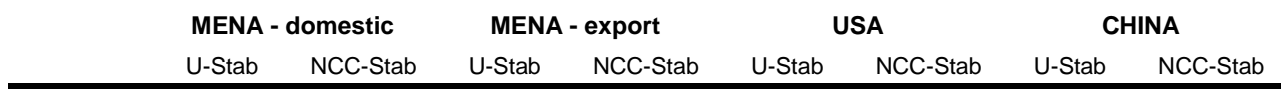

Mirror Surface for generation and storage ('000 sq km)

$\begin{array}{rrrrrrrrr}2040 & 0.1 & 0.5 & - & 0.0 & - & 1.0 & - & 0.6 \\ 2060 & 4.8 & 5.7 & 0.9 & 5.7 & 4.7 & 12.4 & 9.0 & 15.7 \\ 2080 & 8.2 & 8.5 & 3.1 & 8.0 & 15.0 & 16.8 & 18.5 & 22.1 \\ 2100 & 10.6 & 10.5 & 4.1 & 9.2 & 19.6 & 19.5 & 22.7 & 25.5\end{array}$

Number of 5GW HVDC cables for the Super-Grid

$\begin{array}{rrrrrrrrr}2040 & - & - & - & 0.3 & - & 19 & - & 11 \\ 2060 & - & - & 17 & 113 & 92 & 242 & 176 & 307 \\ 2080 & - & - & 61 & 156 & 294 & 329 & 362 & 433 \\ 2100 & - & - & 81 & 181 & 384 & 382 & 446 & 500\end{array}$

Table 6. CSP mirror surface and HVDC cables

\begin{tabular}{|c|c|c|c|c|c|c|c|c|c|}
\hline \multicolumn{10}{|c|}{ List of key parameters } \\
\hline & $\begin{array}{c}\mu_{\mathrm{CSP}} \\
(\mathrm{h})\end{array}$ & $\begin{array}{c}\mu_{\text {grid }} \\
\text { (h) }\end{array}$ & $\begin{array}{c}\mu_{\text {grid, } X} \\
\text { (h) }\end{array}$ & $\begin{array}{l}\mathrm{SC}_{\mathrm{CSP}} \\
(\$ / \mathrm{kW})\end{array}$ & $\begin{array}{l}\mathrm{SC}_{\text {grid }} \\
(\$ / \mathrm{kW})\end{array}$ & $\begin{array}{c}\mathrm{SC}_{\text {grid,X }} \\
(\$ / \mathrm{kW})\end{array}$ & $\begin{array}{c}\mathrm{O} \& \mathrm{M}_{\mathrm{CSP}} \\
(\$ / \mathrm{kW})\end{array}$ & $\begin{array}{c}\text { O\& } M_{\text {grid }} \\
(\$ / k W)\end{array}$ & $\begin{array}{c}\text { O\& } M_{\text {grid, },} \\
(\$ / k W)\end{array}$ \\
\hline CHINA & 4110 & 4110 & & 6500 & 329 & & 127.5 & 6.6 & \\
\hline MENA & 3680 & & 3680 & 6500 & & 336 & 127.5 & & 6.7 \\
\hline USA & 4600 & 4600 & & 6500 & 277 & & 127.5 & 5.5 & \\
\hline
\end{tabular}

Note: the values in \$ are in 2007US\$ as reported in the original data source (Kaltshmitt 2007), these are then converted into 2005US\$ for the model simulations.

Table A1. Assigned values to key parameters. 


\begin{tabular}{|c|c|c|c|c|c|c|c|c|c|c|c|c|c|c|c|c|c|c|}
\hline \multirow{2}{*}{ USA } & \multicolumn{3}{|c|}{ COAL PC } & \multicolumn{4}{|c|}{ COAL IGCC } & \multicolumn{3}{|c|}{ OIL } & \multicolumn{3}{|c|}{ GAS } & \multicolumn{2}{|c|}{ NUKE } & \multirow{2}{*}{\begin{tabular}{|c|} 
HYDRO \\
Capital
\end{tabular}} & \multirow{2}{*}{$\begin{array}{l}\text { W\&S } \\
\text { Capital }\end{array}$} & \multirow{2}{*}{$\frac{\text { CSP }}{\text { Capital }}$} \\
\hline & Capital & Fuel & $\mathrm{CO}_{2}$ & Capital & $\operatorname{ccs}$ & Fuel & $\mathrm{CO}_{2}$ & Capital & Fuel & $\mathrm{CO}_{2}$ & Capital & Fuel & $\mathrm{CO}_{2}$ & Capital & Fuel & & & \\
\hline 2005 & 2,79 & 1,62 & - & 5,37 & 0,49 & 1,35 & - & 2,06 & 7,67 & - & 1,62 & 5,13 & - & 6,05 & 0,14 & & 10,13 & 0,00 \\
\hline 2010 & 2,65 & 1,60 & & 5,07 & 0.49 & 1,38 & & 1,97 & 8,00 & & 1,56 & 4,79 & & 5,84 & 0,16 & 5,24 & 9,30 & 0,00 \\
\hline 2015 & 2,57 & 1,58 & 0,67 & 4,87 & 0,49 & 1,42 & 0,06 & 1,92 & 8,62 & 0,46 & 1,52 & 4,86 & 0,27 & 5,74 & 0,19 & 5,05 & 8,42 & 0,00 \\
\hline 2020 & 2,51 & 1,57 & 1,18 & 4,75 & 0,49 & 1,44 & 0,11 & 1,89 & 9,40 & 0,85 & 1,49 & 5,04 & 0,47 & 5,70 & 0,23 & 4,94 & 7,52 & 0,00 \\
\hline 2025 & 2,46 & 1,55 & 2,57 & 4,63 & 0,49 & 1,47 & 0,24 & 1,85 & 10,35 & 1,96 & 1,47 & 5,29 & 1,04 & 5,67 & 0,30 & 4,82 & 6,65 & 0,00 \\
\hline 2030 & 2,43 & 1,53 & 5,00 & 4,58 & 0,49 & 1,50 & 0,49 & 1,84 & 11,29 & 4,02 & 1,45 & 5,57 & 2,06 & 5,70 & 0,38 & 4,77 & 5,94 & 0,00 \\
\hline 2035 & 2,40 & 1,51 & 7,58 & 4,52 & 0,51 & 1,53 & 0,77 & 1,82 & 12,07 & 6,40 & 1,44 & 5,84 & 3,15 & 5,72 & 0,49 & 4,71 & 5,32 & 0,00 \\
\hline 2040 & 2,37 & 1,50 & 13,52 & 4,43 & 0,53 & 1,56 & 1,40 & 1,80 & 12,66 & 11,94 & 1,42 & 6,11 & 5,68 & 5,76 & 0,62 & 4,63 & 4,74 & 0,00 \\
\hline 2045 & 2.33 & 1.50 & 20.31 & 4.36 & 0.58 & 1.60 & 2.17 & 1.78 & 12.90 & 18.71 & 1.41 & 6.33 & 8.63 & 5.82 & 0.78 & 4.56 & 4.24 & 0.00 \\
\hline 2050 & 2,30 & 1,49 & 30,03 & 4,28 & 0,64 & 1,64 & 3.29 & 1,76 & 12,89 & 28,75 & 1,39 & 6,50 & 12,87 & 5,93 & 0,97 & 4,49 & 3,80 & 11,79 \\
\hline 2055 & 2,30 & 1,49 & 37,51 & 4,28 & 0,70 & 1,67 & 4,22 & 1,76 & 12,64 & 37,22 & 1,39 & 6,62 & 16,23 & 5,98 & 1,21 & 4,49 & 3,51 & 10,36 \\
\hline 2060 & 2,29 & 1,51 & 44,90 & 4,27 & 0,75 & 1,70 & 5,05 & 1,75 & 12,27 & 44,90 & 1,39 & 6,84 & 19,43 & 5,99 & 1,44 & 4,47 & 3,35 & 9,47 \\
\hline 2065 & 2,28 & 1,54 & 50,71 & 4,24 & 0,80 & 1,73 & 5,70 & 1,75 & 11,87 & 51,07 & 1,38 & 7,05 & 21,94 & 5,94 & 1,64 & 4,45 & 3,20 & 8,89 \\
\hline 2070 & 2,27 & 1,56 & 54,64 & 4,22 & 0,84 & 1,75 & 6,15 & 1,74 & 11,45 & 55,39 & 1,38 & 7,28 & 23,65 & 5,92 & 1,78 & 4,43 & 3,08 & 8,52 \\
\hline 2075 & 2,25 & 1,58 & 58,25 & 4,19 & 0,87 & 1,78 & 6,55 & 1,73 & 11,06 & 59,41 & 1,37 & 7,51 & 25,21 & 5,91 & 1,86 & 4,40 & 2,97 & 8,25 \\
\hline 2080 & 2,24 & 1,60 & 61,82 & 4.15 & 0,90 & 1,80 & 6,96 & 1,72 & 10,68 & 63,42 & 1,36 & 7,76 & 26,75 & 5,92 & 1,88 & 4,36 & 2,87 & 8,03 \\
\hline 2085 & 2,22 & 1,62 & 65,04 & 4,11 & 0,92 & 1,82 & 7,32 & 1,71 & 10,31 & 67,09 & 1,36 & 8,02 & 28,15 & 5,95 & 1,86 & 4,33 & 2,77 & 7,85 \\
\hline 2090 & 2,20 & 1,64 & 67,80 & 4,07 & 0,93 & 1,84 & 7,63 & 1,70 & 9,96 & 70,29 & 1,35 & 8,30 & 29,34 & 5,99 & 1,81 & 4,29 & 2,69 & 7,69 \\
\hline 2095 & 2,19 & 1,65 & 69,49 & 4,04 & 0,94 & 1,86 & 7,82 & 1,69 & 9,63 & 72,39 & 1,34 & 8,59 & 30,07 & 6,04 & 1,72 & 4,26 & 2,62 & 7,56 \\
\hline 2100 & 2,18 & 1,67 & 68.34 & 4.01 & 0,95 & 1,88 & 7,69 & 1.69 & 9,32 & 71,52 & 1,34 & 8,89 & 29,58 & 6.10 & 1,61 & 4.24 & 2,56 & 7,46 \\
\hline
\end{tabular}

\begin{tabular}{|c|c|c|c|c|c|c|c|c|c|c|c|c|c|c|c|c|c|c|}
\hline \multirow{2}{*}{ CINA } & \multicolumn{3}{|c|}{ COAL PC } & \multicolumn{4}{|c|}{ COAL IGCC } & \multicolumn{3}{|c|}{ OIL } & \multicolumn{3}{|c|}{ GAS } & \multicolumn{2}{|c|}{ NUKE } & \multirow{2}{*}{\begin{tabular}{|c|} 
HYDRO \\
Capital \\
\end{tabular}} & \multirow{2}{*}{ W\&S } & \multirow{2}{*}{$\frac{\text { CSP }}{\text { Capital }}$} \\
\hline & Capital & Fuel & $\mathrm{CO}_{2}$ & Capital & $\operatorname{ccs}$ & Fuel & $\mathrm{CO}_{2}$ & Capital & Fuel & $\mathrm{CO}_{2}$ & Capital & Fuel & $\mathrm{CO}_{2}$ & Capital & Fuel & & & \\
\hline 2005 & 2,62 & 1,60 & & 6,04 & 0,49 & 1,22 & - & 2,63 & 10,31 & - & 2,14 & 5,70 & - & 6,57 & 0,14 & & 11,59 & 0,00 \\
\hline 2010 & 3,14 & 1,57 & & 7,41 & 0,49 & 1.26 & & 3,07 & 10,68 & & 2,50 & 5,26 & & 7,70 & 0,16 & 7,57 & 13,48 & 0,00 \\
\hline 2015 & 3,18 & 1,54 & 0,71 & 7,52 & 0,49 & 1,29 & 0,06 & 3,11 & 11,40 & 0,53 & 2,53 & 5,27 & 0,29 & 7,85 & 0,19 & 7,67 & 12,77 & 0,00 \\
\hline 2020 & 3,06 & 1,51 & 1,25 & 7,20 & 0,4 & 1,32 & 0,11 & 3,0 & 12 & 0,99 & 2,4 & 5 & 0,51 & 76 & $0,2 J$ & 7,37 & 11,00 & 0,00 \\
\hline 2025 & 2,89 & 1,48 & 2,69 & 6,76 & 0,49 & 1,35 & 0,24 & 2,86 & 13,39 & 2,26 & 2,33 & 5,6 & 1,11 & 7,36 & 0,30 & 6,95 & 9,27 & 0,00 \\
\hline 2030 & 2,76 & 1,45 & 5,19 & 6,43 & 0,49 & 1,37 & 0,49 & 2,76 & 14,48 & 4,63 & 2,24 & 5,84 & 2,15 & 7,16 & 0,38 & 6,63 & 8,02 & 0,00 \\
\hline 2035 & 2,66 & 1,43 & 7,80 & 6,16 & 0,50 & 1,40 & 0,77 & 2,67 & 15,38 & 7,37 & 2,18 & 6,06 & 3,27 & 7,02 & 0,49 & 6,38 & 7,00 & 0,00 \\
\hline 2040 & 2,54 & 1,41 & 13,80 & 5,84 & 0,54 & 1,44 & 1,40 & 2,57 & 16,05 & 13,76 & 2,09 & 6,28 & 5,84 & 6,88 & 0,62 & 6,08 & 6,06 & 0,00 \\
\hline 2045 & 2.43 & 1.40 & 20.59 & 5.55 & 0.66 & 1.47 & 2.17 & 2.48 & 16.34 & 21.57 & 2.02 & 6.4 & 8.78 & & 0.78 & & & 0.00 \\
\hline 2050 & 2,30 & 1,39 & 30,22 & 5,20 & 0,96 & 1,51 & 3,29 & 2,37 & 16 & 33,15 & 1,93 & 6 & $\begin{array}{l}12,98 \\
128\end{array}$ & & 0, & 5, & & 15,54 \\
\hline 2055 & 2,27 & 1,37 & 37,51 & 5,11 & 1,4 & 1,55 & 4,22 & 2,34 & & 42,90 & 1,9 & & 16,23 & & & & & 13,63 \\
\hline 2060 & 2,22 & 1,40 & 44,90 & 4,98 & 2,03 & 1,58 & 5,05 & 2,29 & 15,61 & 51,77 & 1,87 & 6,8 & 19,43 & 6,5 & $\begin{array}{l}1,21 \\
1,44\end{array}$ & 5,26 & 3,86 & 12,35 \\
\hline 2065 & 2,16 & 1,43 & 50,71 & 4,84 & 2,7 & 1,60 & 5,70 & 2,2 & 15 & 58,88 & 1.8 & 1, & 21,94 & 6. & 1.6 & & 3,63 & 11,48 \\
\hline 2070 & 2,11 & 1,4 & 54,64 & & 3 & 1,6 & 6,15 & 2,2 & & 63,86 & & & 23,65 & & & & 3,43 & 10,84 \\
\hline 2075 & 2,06 & 1.47 & 58,25 & 4,5 & 4,26 & 1.65 & 6,55 & 2,16 & 14 & 68,48 & 1,76 & 7,5 & 25,21 & 6,2 & 1,86 & 4.8 & 3,25 & 10,34 \\
\hline 2080 & 2,01 & 1,49 & 61,82 & 4,44 & 4,96 & 1,67 & 6,96 & 2,12 & 13,77 & 73,11 & 1,73 & 7,7 & 26,75 & 6,1 & 1,88 & 4,7 & 3,09 & 9,94 \\
\hline 2085 & 1,97 & 1,451 & 65,04 & $\begin{array}{l}4,474 \\
4,33\end{array}$ & 5,58 & 1,70 & 7,32 & 2,09 & 13,35 & 77,34 & 1,7 & 8,0 & 28,15 & 6, & $\begin{array}{l}1,86 \\
1,86\end{array}$ & 4, & 2,96 & 9,63 \\
\hline 2090 & 1,93 & 1,53 & $\begin{array}{l}63,04 \\
67,80\end{array}$ & $\begin{array}{l}4,350 \\
4,23\end{array}$ & 6 & $\begin{array}{l}1,10 \\
1,72\end{array}$ & $\begin{array}{l}7,32 \\
7,63\end{array}$ & 2,05 & $\begin{array}{l}15,35 \\
12,95\end{array}$ & $\begin{array}{l}81,03 \\
81,03\end{array}$ & 1,6 & 8, & $\begin{array}{l}29,35 \\
29,34\end{array}$ & 6. & 1,8 & $\begin{array}{l}4,0 \\
4,5\end{array}$ & 2,84 & 9,37 \\
\hline 2095 & 1,90 & 1,54 & 69,49 & 4,14 & 6,5 & 1,74 & 7,82 & 2,02 & 12,5 & 83,46 & 1,65 & 8,5 & 30,07 & 6,1 & 1,72 & 4,45 & 2,74 & 9,15 \\
\hline 2100 & 1,87 & $\begin{array}{l}1,54 \\
\end{array}$ & 68,34 & 4.07 & 6.90 & 1,76 & $\begin{array}{l}7,62 \\
7.69\end{array}$ & 2,00 & $\begin{array}{l}12,21 \\
12,21\end{array}$ & 82,45 & 1,63 & 8,89 & 29,58 & 6.12 & $\begin{array}{l}1,61 \\
1,61\end{array}$ & $\begin{array}{r}4,45 \\
4,39\end{array}$ & 2,65 & 8.97 \\
\hline
\end{tabular}

\begin{tabular}{|c|c|c|c|c|c|c|c|c|c|c|c|c|c|c|c|c|c|c|}
\hline \multirow{2}{*}{ MENA } & \multicolumn{3}{|c|}{ COAL PC } & \multicolumn{4}{|c|}{ COAL IGCC } & \multicolumn{3}{|c|}{ OIL } & \multicolumn{3}{|c|}{ GAS } & \multicolumn{2}{|c|}{ NUKE } & \multirow{2}{*}{\begin{tabular}{|c|} 
HYDRO \\
Capital \\
\end{tabular}} & \multirow{2}{*}{\begin{tabular}{l|} 
W\&S \\
Capital
\end{tabular}} & \multirow{2}{*}{$\frac{\text { CSP }}{\text { Capital }}$} \\
\hline & Capital & Fuel & $\mathrm{CO}_{2}$ & Capital & $\operatorname{ccs}$ & Fuel & $\mathrm{CO}_{2}$ & Capital & Fuel & $\mathrm{CO}_{2}$ & Capital & Fuel & $\mathrm{CO}_{2}$ & Capital & Fuel & & & \\
\hline 2005 & 3,62 & 2,31 & - & 6,07 & 0,98 & 2,22 & - & 2,60 & 3,83 & - & 2,13 & 2,67 & - & 6,91 & 0,14 & 6,51 & 111,05 & 0,00 \\
\hline 2010 & 3,53 & 2,31 & & 5,91 & 0,98 & 2,26 & & 2,55 & 4,15 & & 2,09 & 2,25 & & 6,81 & 0,16 & 6,35 & 10,43 & 0,00 \\
\hline 2015 & 3,42 & 2,30 & 0,60 & 5,71 & 0,98 & 2,29 & 0,06 & 2,48 & 4,77 & 0,46 & 2,03 & 2,34 & 0,31 & 6,71 & 0,19 & 6,16 & 9,44 & 0,00 \\
\hline 2020 & 3,35 & 2,29 & 1,08 & 5,59 & 0,98 & 2,32 & 0,11 & 2,4 & 5,5 & 0,85 & 20 & & 0,55 & 6,67 & & & 8,39 & 0,00 \\
\hline 2025 & 3,27 & 2,28 & 2,38 & 5. & 0,9 & 2,3 & 0 & 2,4 & 6,4 & 1,94 & 1,96 & 2, & 1,17 & 6,6 & 0,30 & 5, & 7,34 & .00 \\
\hline 2030 & 3,18 & 2,27 & 4,69 & 5,27 & 0,98 & 2,37 & 0,49 & 2,34 & 7,42 & 3,98 & 1,92 & 3,13 & 2,26 & 6,55 & 0,38 & 5,74 & 6,38 & 0,00 \\
\hline 2035 & 3,15 & 2,27 & 7,22 & 5,22 & 0,98 & 2,40 & 0,77 & 2,33 & 8,19 & 6,34 & 1,91 & 3,41 & 3,40 & 6,58 & 0,49 & 5,70 & 5,70 & 0,00 \\
\hline 2040 & 3,09 & 2,26 & 13,04 & 5,09 & 0,98 & 2,44 & 1,40 & 2,29 & 8,77 & 11,83 & 1,87 & 3,68 & 6,00 & 6,59 & 0,62 & 5,58 & 5,02 & 26,49 \\
\hline 2045 & 3.10 & 2.26 & 19.84 & 5.12 & 0.98 & 2.47 & 2.17 & 2.29 & 9.01 & 18.54 & 1.88 & 3.87 & 8.93 & 6.73 & 0.78 & & 4.65 & 19.97 \\
\hline 2050 & 3,10 & 2,27 & 29,68 & 5,12 & 0,98 & 2,51 & 3,29 & 2,29 & 9,00 & 28,49 & 1,88 & 4,02 & 13,10 & & 0,97 & & & 16,20 \\
\hline 2055 & 3,08 & 2,26 & 37,51 & 5,09 & 0,98 & 2,55 & 4,22 & 2,28 & 8,7 & 36,88 & 1,8 & 4,12 & 16,23 & 6 & 1,2 & 5 & 4,02 & 14,13 \\
\hline 2060 & 3,08 & 2,29 & 44,90 & 5,09 & 0,9 & 2. & 5,05 & 2,2 & & 44,50 & & & 19,43 & & & 5, & 3 & 12,36 \\
\hline 2065 & 3,07 & 2,31 & 50,71 & 5,06 & 0,98 & 2,60 & 5,70 & 2,2 & 7,99 & 50,61 & 1,8 & 4,5 & 21,94 & 6,9 & 1,6 & 5,5 & 3,66 & 11,30 \\
\hline 2070 & 3,05 & 2,34 & 54,64 & 5,0 & 098 & 2,63 & 6,15 & 2, & 7,58 & 54,89 & & 4,7 & 23,6 & & & & 3,48 & 10,58 \\
\hline 2075 & 3,02 & 2,3 & & & 0 & 2,65 & 6,55 & 2,2 & 7,1 & 58,87 & & 5,0 & 25,21 & 6, & 1,8 & 0, & 3,32 & 10,05 \\
\hline 2080 & 2,99 & 2,38 & 61,82 & 4,91 & 0,98 & 2,67 & 6,96 & 2,23 & 6,81 & 62,85 & 1,83 & 5,2 & 26,75 & 6,8 & 1,88 & 5,40 & 3,18 & 9,65 \\
\hline 2085 & 2,96 & 2,40 & 65,04 & 4,86 & 0,98 & 2,70 & 7,32 & 2,21 & 6,44 & 66,48 & 1,81 & 5,52 & 28,15 & 6,8 & 1,8 & 5, & 3, & 9,33 \\
\hline 2090 & 2,93 & 2,41 & 67,80 & $\begin{array}{l}4,81 \\
4,81\end{array}$ & 0,98 & 2,72 & 7,63 & 2,19 & 6,40 & 69,66 & 1,8 & 5,8 & 29,34 & 6,88 & 1,8 & 5,3 & 2,96 & 9,07 \\
\hline 2095 & 2,91 & 2,43 & 69,49 & 4,77 & 0.98 & 2,74 & 7,82 & 2,1 & 5,7 & 71,74 & 1,7 & 6,0 & 30,07 & 6 & 1,7 & 5,2 & 2,8 & 8,86 \\
\hline 2100 & 2,89 & 2,45 & 68,34 & 4,73 & 0,98 & 2,76 & 7,69 & 2.17 & 5,46 & 70,88 & 1.78 & 6,39 & 29,58 & 6.97 & 1,61 & 5,23 & 2,80 & 8,70 \\
\hline
\end{tabular}

\begin{tabular}{|c|c|c|c|c|c|c|c|c|c|c|c|c|c|c|c|c|c|c|}
\hline \multirow{2}{*}{$\begin{array}{l}\text { Western } \\
\text { Europe }\end{array}$} & \multicolumn{3}{|c|}{ COAL PC } & \multicolumn{4}{|c|}{ COAL IGCC } & \multicolumn{3}{|c|}{ OIL } & \multicolumn{3}{|c|}{ GAS } & \multicolumn{2}{|c|}{ NUKE } & \multirow{2}{*}{\begin{tabular}{|c|} 
HYDRO \\
Capital
\end{tabular}} & \multirow{2}{*}{$\frac{\text { W\&S }}{\text { Capital }}$} & \multirow{2}{*}{$\frac{\text { CSP }}{\text { Import }}$} \\
\hline & Capital & Fuel & $\mathrm{CO}_{2}$ & Capital & $\operatorname{ccs}$ & Fuel & $\mathrm{CO}_{2}$ & Capital & Fuel & $\mathrm{CO}_{2}$ & Capital & Fuel & $\mathrm{CO}_{2}$ & Capital & Fuel & & & \\
\hline 2005 & 2.98 & 2.98 & 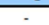 & 5,54 & 0.49 & 2.77 &. & 2.35 & 10,54 & $\because$ & 1.85 & 4.13 & . & 6.18 & 0.14 & 5,71 & 10.14 & . \\
\hline 2010 & 2,85 & 2,96 & & 5,25 & 0,49 & 2,81 & & 2,26 & 10,86 & - & 1,78 & 3,81 & & 5,98 & 0,16 & 5,43 & 9,34 & - \\
\hline 2015 & 2,76 & 2,93 & 0,62 & 5.06 & 0,49 & 2,84 & 0,06 & 2,21 & 11,49 & 0.46 & 1,74 & 3,90 & 0,27 & 5,89 & 0,19 & 5,26 & 8,50 & - \\
\hline 2020 & 2,71 & 2,90 & 1,10 & 4,94 & 0,49 & 2,87 & 0,11 & 2,17 & 12,28 & 0,86 & 1,71 & 4,10 & 0,47 & 5,85 & 0,23 & 5,14 & 7,60 & - \\
\hline 2025 & 2,66 & 2,87 & 2,42 & 4,84 & 0,49 & 2,90 & 0.24 & 2,14 & 13,23 & 1,97 & 1,68 & 4.37 & 1,04 & 5,83 & 0,30 & 5,04 & 6,75 & - \\
\hline 2030 & 2,63 & 2,85 & 4,77 & 4,78 & 0.49 & 2,92 & 0.49 & 2,12 & 14.18 & 4,05 & 1,67 & 4,66 & 2,06 & 5,85 & 0,38 & 4,99 & 6,03 & - \\
\hline 2035 & 2,61 & 2,82 & 7,31 & 4,73 & 0,49 & 2,95 & 0,77 & 2,10 & 14.97 & 6.44 & 1,66 & 4,95 & 3,15 & 5,88 & 0.49 & 4.94 & 5.41 & - \\
\hline 2040 & 2,57 & 2,80 & 13,16 & 4,66 & 0.49 & 2,99 & 1,40 & 2,08 & 15,55 & 12,02 & 1,64 & 5,2 & 5,68 & 5,93 & 0,62 & 4.87 & 4.84 & - \\
\hline 2045 & 2.55 & 2.79 & 19.96 & 4.60 & 0.50 & 3.02 & 2.17 & 2.07 & 15 & 18.84 & 1.6 & & 8.63 & & & & 4.36 & - \\
\hline 2050 & 2,52 & 2,77 & 29,77 & 4,54 & 0,50 & 3,06 & 3,29 & 2,05 & 15,79 & 28,95 & 1,62 & 5,6 & 12,87 & & 0,9 & & & . \\
\hline 2055 & 2,50 & 2,75 & 37,51 & $\begin{array}{l}4,54 \\
4,50\end{array}$ & 0,51 & 3,10 & $\begin{array}{l}4,25 \\
4,22\end{array}$ & 2,03 & 15,53 & $\begin{array}{l}20,050 \\
37,47\end{array}$ & $\begin{array}{l}1,02 \\
1,61\end{array}$ & $\begin{array}{l}5,05 \\
5,79\end{array}$ & $\begin{array}{l}12,010 \\
16,23\end{array}$ & $6,6,15$ & $\frac{1,97}{1,21}$ & $\begin{array}{l}4,16 \\
4,73\end{array}$ & $\begin{array}{l}3,65 \\
3,66\end{array}$ & - \\
\hline 2060 & 2,49 & 2,78 & 44,90 & 4,47 & 0,51 & 3,13 & 5,05 & 2,02 & 15,17 & 45,21 & 1,60 & 6,0 & 19,43 & 6,14 & 1,44 & 4,69 & 3,47 & 13,45 \\
\hline 2065 & 2,47 & 2,80 & 50,71 & 4,44 & 0,51 & 3,15 & 5,70 & 2.01 & 14,76 & 51,42 & 1.5 & 6.22 & 21,94 & 6,09 & 1,64 & 4 & 3,31 & 12.41 \\
\hline 2070 & 2,46 & 2,82 & 54,64 & 4.41 & 0.51 & 3,18 & 6.15 & 2,00 & 14,34 & 55,77 & 1,58 & 6.44 & 23,65 & 6.06 & 1,78 & 4.63 & 3,17 & 11,79 \\
\hline 2075 & $\begin{array}{l}2,40 \\
2,44\end{array}$ & $\begin{array}{l}2,02 \\
2,85\end{array}$ & $\begin{array}{l}54,64 \\
58,25\end{array}$ & $\begin{array}{l}4,4 \\
4,3\end{array}$ & $\begin{array}{l}0,51 \\
0,52\end{array}$ & $\begin{array}{l}3,10 \\
3,20\end{array}$ & $\begin{array}{l}6,15 \\
6,55\end{array}$ & $\begin{array}{l}2,90 \\
1,99\end{array}$ & $\begin{array}{l}44,34 \\
13,94\end{array}$ & $\begin{array}{l}55,17 \\
59,82\end{array}$ & $\begin{array}{l}1,5 \\
1,5\end{array}$ & 6,6 & $\begin{array}{l}25,65 \\
25,21\end{array}$ & 6,0 & $\begin{array}{l}1,10 \\
1,86\end{array}$ & $\begin{array}{l}4,63 \\
4,60\end{array}$ & 3,17 & 11,38 \\
\hline 2080 & $\begin{array}{l}2,444 \\
2,42\end{array}$ & $\begin{array}{l}2,85 \\
2.87\end{array}$ & $\begin{array}{l}58,255 \\
61,82\end{array}$ & $\begin{array}{l}4,37 \\
4,33\end{array}$ & $\begin{array}{l}0,52 \\
0.52\end{array}$ & $\begin{array}{l}3,20 \\
3,22\end{array}$ & $\begin{array}{l}6,55 \\
6.96\end{array}$ & $\begin{array}{l}1,9 \\
1,9\end{array}$ & $\begin{array}{l}\text { 13, } \\
13,\end{array}$ & $\begin{array}{l}59,82 \\
63.86\end{array}$ & $\begin{array}{l}1,5 \\
1.5\end{array}$ & 6,6 & $\begin{array}{l}26,27 \\
26,75\end{array}$ & $6,0,0$ & $\frac{1}{1}$ & $\begin{array}{l}4,60 \\
4.56\end{array}$ & $\begin{array}{l}3,04 \\
2,93\end{array}$ & $\begin{array}{l}11,38 \\
11,08\end{array}$ \\
\hline 2085 & $\begin{array}{l}2,42 \\
2,41\end{array}$ & 2,88 & 65,04 & 4,30 & 0,52 & 3,25 & 7,32 & 1,9 & 13, & 67,55 & 1,5 & 7,1 & 28,15 & 6,1 & 1,8 & 4,5 & 2,83 & $\begin{array}{l}10,07 \\
\end{array}$ \\
\hline 2090 & 2,39 & 2,90 & 67,80 & 4,26 & 0,52 & 3,27 & 7,63 & 1.9 & 12 & 70,78 & 1.5 & 7.4 & 29.34 & 6.1 & 1,8 & 4.4 & 2,74 & 10,70 \\
\hline 2095 & 2,37 & 2,92 & 69,49 & 4,22 & 0,52 & 3,29 & 7,82 & 1,95 & 12,51 & 72,89 & 1,54 & 7,7 & 30,07 & 6,18 & 1,72 & 4,46 & 2,66 & 10,57 \\
\hline 2100 & 2,36 & 2,94 & 68,34 & 4.19 & 0,52 & 3,31 & 7,69 & 1,94 & 12,19 & 72,02 & 1,53 & 8,06 & 29,58 & 6,23 & 1,61 & 4,43 & 2,59 & 10,44 \\
\hline
\end{tabular}




\begin{tabular}{|c|c|c|c|c|c|c|c|c|c|c|c|c|c|c|c|c|c|c|}
\hline \multirow{2}{*}{$\begin{array}{l}\text { Eastern } \\
\text { Europe }\end{array}$} & \multicolumn{3}{|c|}{ COAL PC } & \multicolumn{4}{|c|}{ COAL IGCC } & \multicolumn{3}{|c|}{ OIL } & \multicolumn{3}{|c|}{ GAS } & \multicolumn{2}{|c|}{ NUKE } & \multirow{2}{*}{\begin{tabular}{|c|} 
HYDRO \\
Capital
\end{tabular}} & \multirow{2}{*}{$\begin{array}{l}\text { W\&S } \\
\text { Capital }\end{array}$} & \multirow{2}{*}{$\frac{\text { CSP }}{\text { Import }}$} \\
\hline & Capital & Fuel & $\mathrm{CO}_{2}$ & Capital & $\operatorname{ccs}$ & Fuel & $\mathrm{CO}_{2}$ & Capital & Fuel & $\mathrm{CO}_{2}$ & Capital & Fuel & $\mathrm{CO}_{2}$ & Capital & Fuel & & & \\
\hline 2005 & 2,54 & 2,18 & & 5,20 & 0.29 & 1,72 & & 2,36 & 10,74 & & 2,03 & 4,13 & 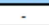 & 6,24 & 0,14 & 5,24 & 10,13 & - \\
\hline 2010 & 2,82 & 2,13 & & 5,85 & 0,29 & 1,76 & & 2,56 & 11,13 & & 2,20 & 3,81 & & 6,80 & 0,16 & 5,86 & 10,88 & - \\
\hline 2015 & 2,85 & 2,09 & 0,70 & 5,93 & 0,29 & 1,79 & 0,06 & 2,58 & 11,87 & 0,55 & 2,22 & 3,90 & 0,27 & 6,92 & 0,19 & 5,94 & 10,31 & - \\
\hline 2020 & 2,81 & 2,04 & 1,22 & 5,83 & 0,29 & 1,82 & 0,11 & 2,55 & 12,81 & 1,03 & 2,20 & 4.10 & 0.47 & 6,89 & 0,23 & 5,84 & 9,22 & - \\
\hline 2025 & 2.74 & 2.00 & 2,64 & 5.67 & 0.29 & 1.85 & 0,24 & 2.50 & 13,94 & 2,35 & 2,15 & 4,37 & 1,04 & 6.83 & 0,30 & 5,69 & 8.15 & . \\
\hline 2030 & 2,65 & 1,95 & 5,11 & 5,46 & 0.29 & 1,87 & 0,49 & 2,44 & 15,08 & 4,82 & 2,10 & 4,66 & 2,06 & 6,73 & 0,38 & 5,49 & 7,10 & . \\
\hline 2035 & 2,55 & 1,92 & 7,71 & 5,24 & 0,30 & 1,90 & 0,77 & 2,37 & 16,02 & 7,68 & 2,04 & 4,95 & 3,15 & 6,63 & 0,49 & 5,28 & 6,20 & - \\
\hline 2040 & 2,47 & 1,89 & 13,69 & 5,04 & 0,30 & 1,94 & 1,40 & 2,31 & 16,72 & 14,33 & $\begin{array}{l}2,04 \\
1.99\end{array}$ & 5,24 & 5,68 & 6.57 & 0,62 & 5.09 & 5,43 & . \\
\hline 2045 & 2.40 & 1.87 & 20.48 & 4.88 & 0.31 & 1.97 & 2.17 & 2.26 & 17.01 & 22.46 & 1.94 & 5.47 & 8.63 & 6.56 & 0.78 & 4.93 & 4.80 & - \\
\hline 2050 & 2,32 & 1.84 & 30,15 & 4.71 & 0.33 & 2.01 & 3.29 & 2,20 & 17,00 & 34.52 & 1.90 & 5,65 & 12,87 & 6.60 & 0.97 & 4.77 & 4.25 & 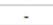 \\
\hline 2055 & 2,29 & 1,82 & 37,51 & 4,63 & 0,36 & 2,05 & 4,22 & 2,18 & 16,70 & 44,68 & 1,88 & 5,79 & 16,23 & 6,59 & 1,21 & 4,70 & 3,81 & \\
\hline 2060 & 2,26 & $\begin{array}{l}1,02 \\
1,85\end{array}$ & 44,90 & $\begin{array}{l}4,05 \\
4,56\end{array}$ & $\begin{array}{l}0,30 \\
0,39\end{array}$ & $\begin{array}{l}2,05 \\
2,08\end{array}$ & $\begin{array}{l}4,22 \\
5,05\end{array}$ & 2,16 & $\begin{array}{l}10,26 \\
16,26\end{array}$ & 53,91 & $\begin{array}{l}1,00 \\
1,86\end{array}$ & 6,01 & 19,43 & 6,55 & $\begin{array}{l}1,47 \\
1,44\end{array}$ & $\begin{array}{l}4,10 \\
4,63\end{array}$ & 3,59 & 13,45 \\
\hline 2065 & $\begin{array}{l}2,26 \\
2,23\end{array}$ & $\begin{array}{l}1,05 \\
1,87\end{array}$ & $\begin{array}{l}44,90 \\
50,71\end{array}$ & $\begin{array}{l}4,56 \\
4,49\end{array}$ & 0.42 & $\begin{array}{l}2,00 \\
2,10\end{array}$ & $\begin{array}{l}5,03 \\
5,70\end{array}$ & 2,14 & $\begin{array}{l}10,260 \\
15,77\end{array}$ & $\begin{array}{l}53,91 \\
61,32\end{array}$ & $\begin{array}{l}1,06 \\
1.84\end{array}$ & $\begin{array}{l}6,01 \\
6,22\end{array}$ & $\begin{array}{r}19,43 \\
21,94\end{array}$ & $\begin{array}{l}6,05 \\
6,47\end{array}$ & $\begin{array}{l}1,44 \\
1,64\end{array}$ & $\begin{array}{l}4,05 \\
4,56\end{array}$ & $\begin{array}{l}3,59 \\
3,42\end{array}$ & $\begin{array}{r}5,45 \\
12,41\end{array}$ \\
\hline 2070 & 2,20 & 1,89 & 54,64 & $\begin{array}{l}4,47 \\
4,42\end{array}$ & 0,45 & 2,13 & 6,15 & 2,11 & 15,27 & 66,50 & 1,82 & 6,44 & 23,65 & 6,40 & 1,78 & 4,50 & 3,27 & 11,79 \\
\hline 2075 & 2,16 & 1,91 & 58,25 & $\begin{array}{l}4,424 \\
4,34\end{array}$ & 0,47 & 2,15 & 6,55 & 2,09 & 14,80 & 71,32 & $\begin{array}{l}1,02 \\
1,80\end{array}$ & $6,6,44$ & 25,21 & $\begin{array}{l}6,400 \\
6,36\end{array}$ & $\begin{array}{l}1,106 \\
1,86\end{array}$ & $\begin{array}{l}4,50 \\
4,42\end{array}$ & $\begin{array}{l}3,27 \\
3,13\end{array}$ & $\begin{array}{l}11,19 \\
11,38\end{array}$ \\
\hline 2080 & 2,13 & 1,93 & 61,82 & 4,26 & 0,50 & 2,17 & 6,96 & 2,06 & 14,34 & 76,14 & 1,78 & 6,93 & 26,75 & 6,34 & 1,88 & $\begin{array}{r}4,42 \\
4,34\end{array}$ & 3,00 & 11,08 \\
\hline 2085 & 2,10 & 1,95 & 65,04 & 4,18 & 0,51 & 2,20 & 7,32 & 2,04 & 13,90 & 80,55 & 1,76 & 7,19 & 28,15 & 6,34 & 1,86 & 4.27 & 2,89 & 10,87 \\
\hline 2090 & 2,07 & 1,97 & 67,80 & 4,11 & 0,53 & 2,22 & 7,63 & 2,02 & 13,49 & 84,40 & 1,74 & 7,46 & 29,34 & 6,35 & 1,81 & 4,20 & 2,78 & 10,70 \\
\hline 2095 & 2,04 & 1,99 & 69.49 & 4.04 & 0,54 & 2,24 & 7,82 & 2,00 & 13,09 & 86.92 & 1,72 & 7,75 & 30,07 & 6.37 & 1,72 & 4,14 & 2,69 & 10,57 \\
\hline 2100 & 2,04 & 200 & 68.34 & $\begin{array}{l}4,04 \\
3.98\end{array}$ & 0,55 & 226 & $\begin{array}{l}7,62 \\
7.69\end{array}$ & 1,98 & 1271 & 85,87 & 1,70 & 8.06 & 29,58 & 6,40 & 1,61 & $\begin{array}{l}4,14 \\
4,08\end{array}$ & 2,61 & 10,44 \\
\hline
\end{tabular}

Notes: Capital costs also include costs for operation and maintenance. The above tables refer to the unconstrained stabilization scenario (U-Stab). Similar tables for all other scenarios are available upon request.

Table A2. The cost of electricity in the U-Stab scenario. 


\section{List of Figures}

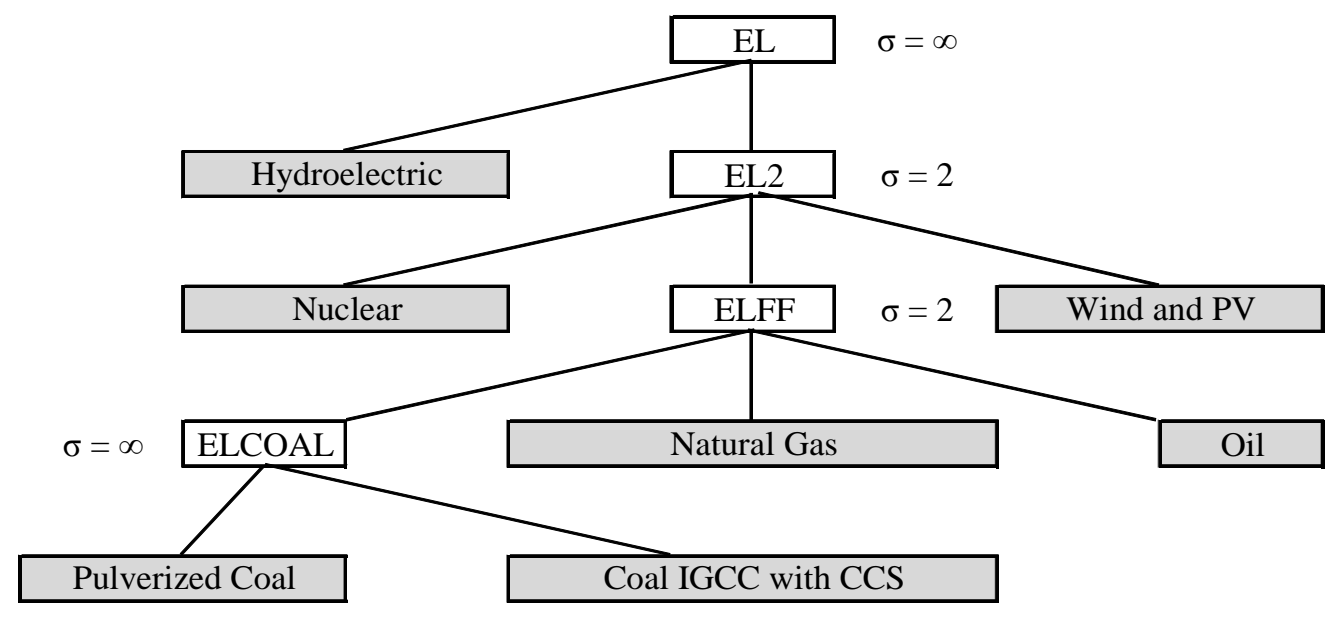

Notes: Elasticities of substitution $\sigma$ are detailed at each nest. Electricity is measured in energy units. Electricity generation follows a Leontief specification.

Figure 1. The constant elasticity of substitution nested structure of electricity supply. 

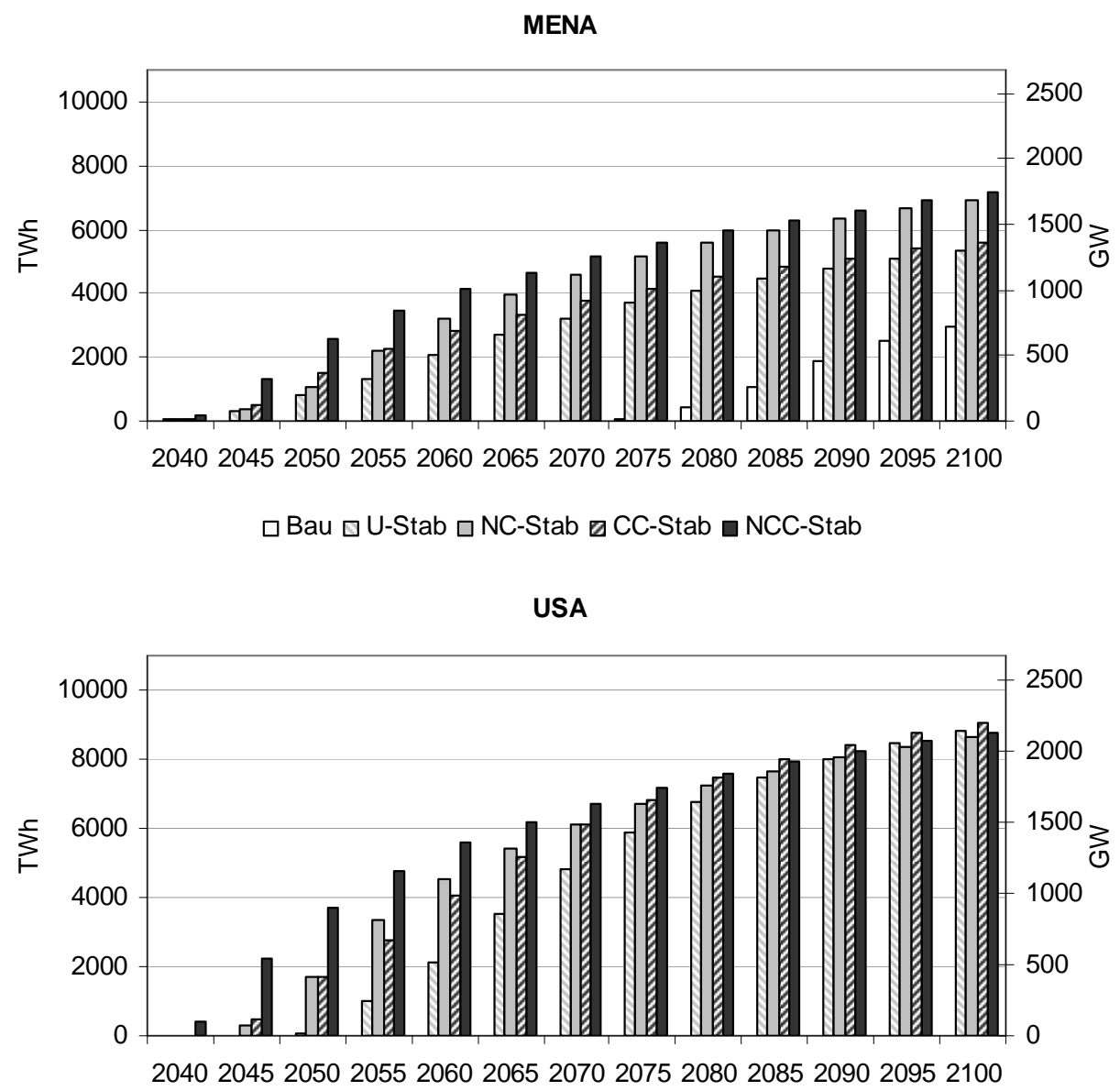

$\square$ Bau $\square$ U-Stab $\square$ NC-Stab $\square$ CC-Stab $\square$ NCC-Stab

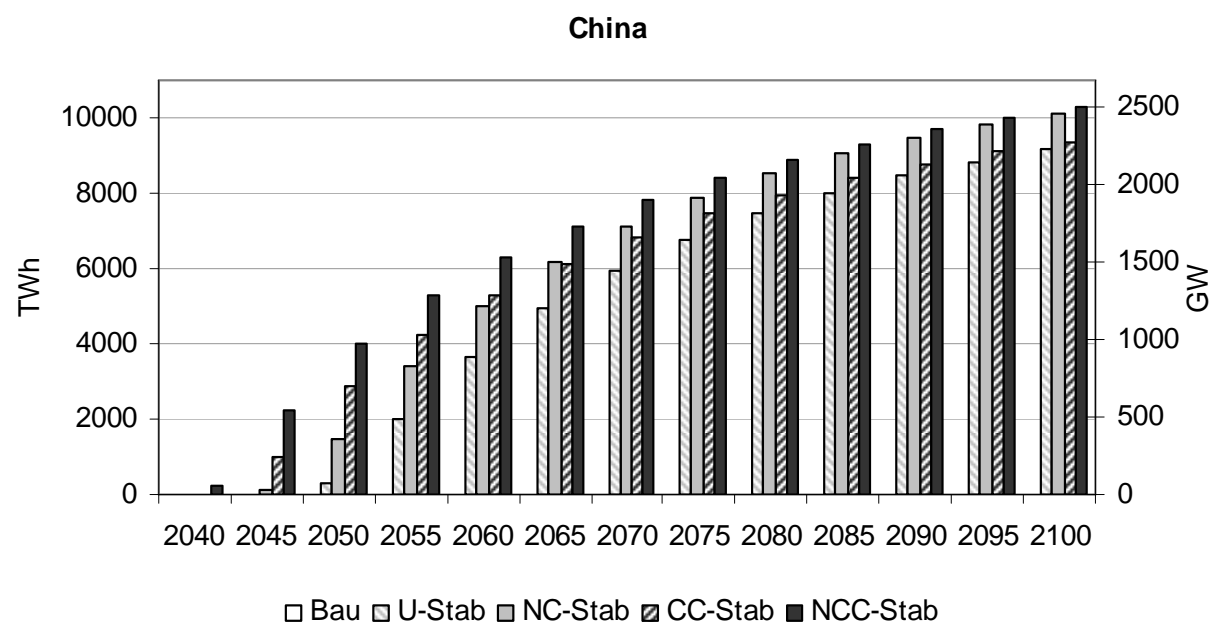

Figure 2. CSP Installed Capacity and Electricity Generation 


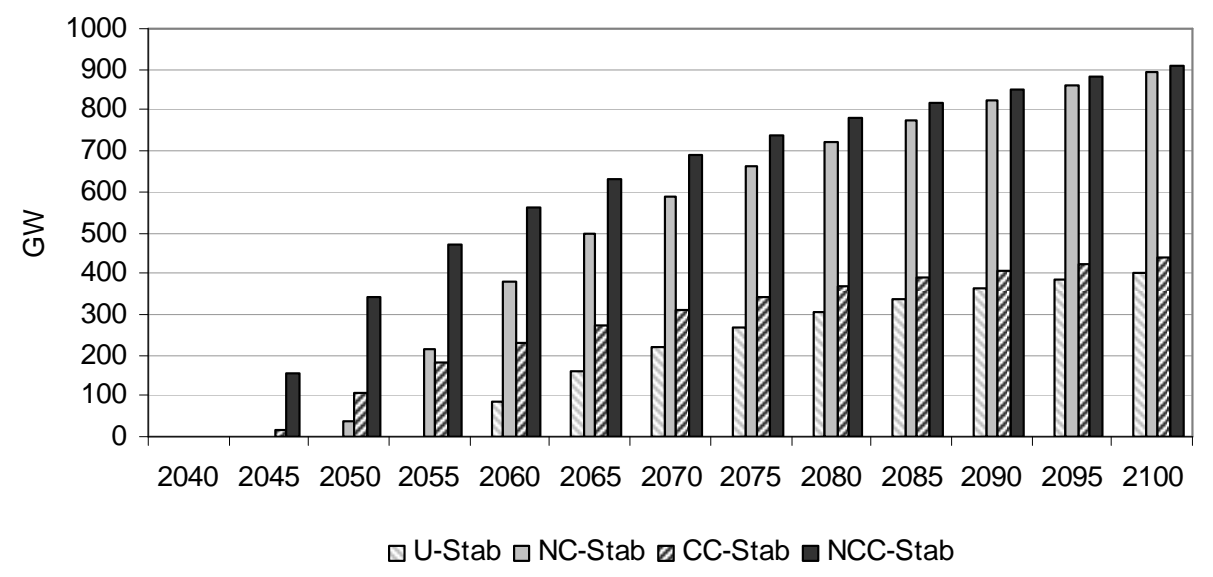

Figure 3. Super-Grid Installed Capacity between Europe and the MENA Region.
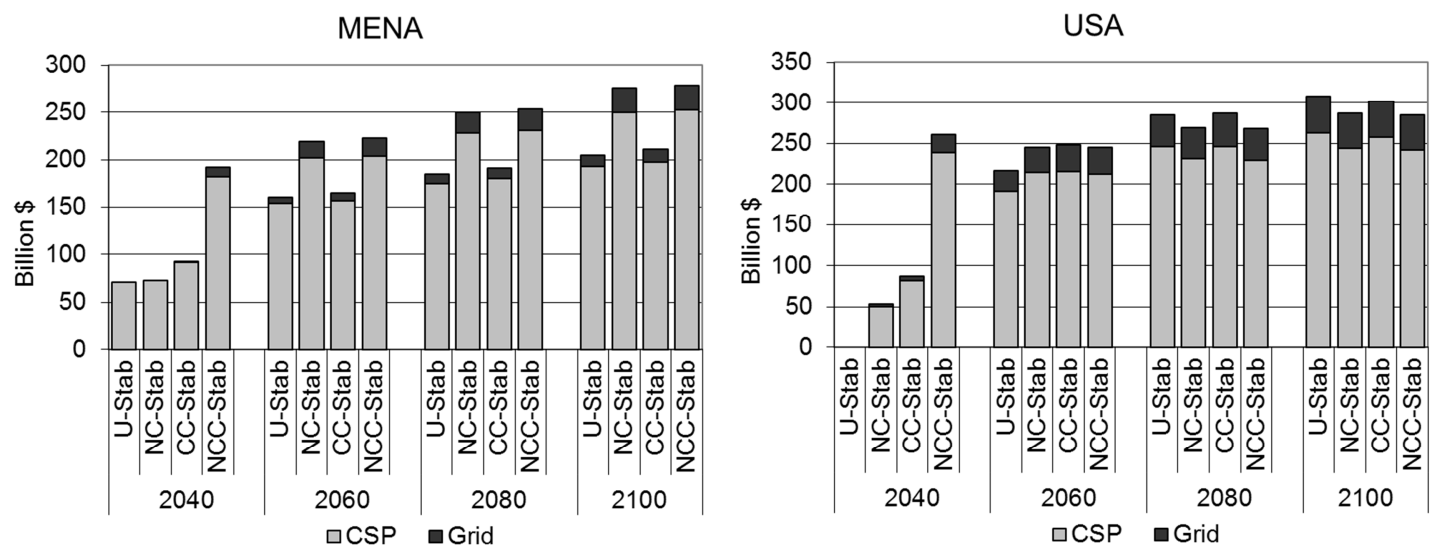

Figure 4. Investments for CSP-Plants and the Super-Grid Infrastructure - MENA and the USA

\section{CSP Investment costs}

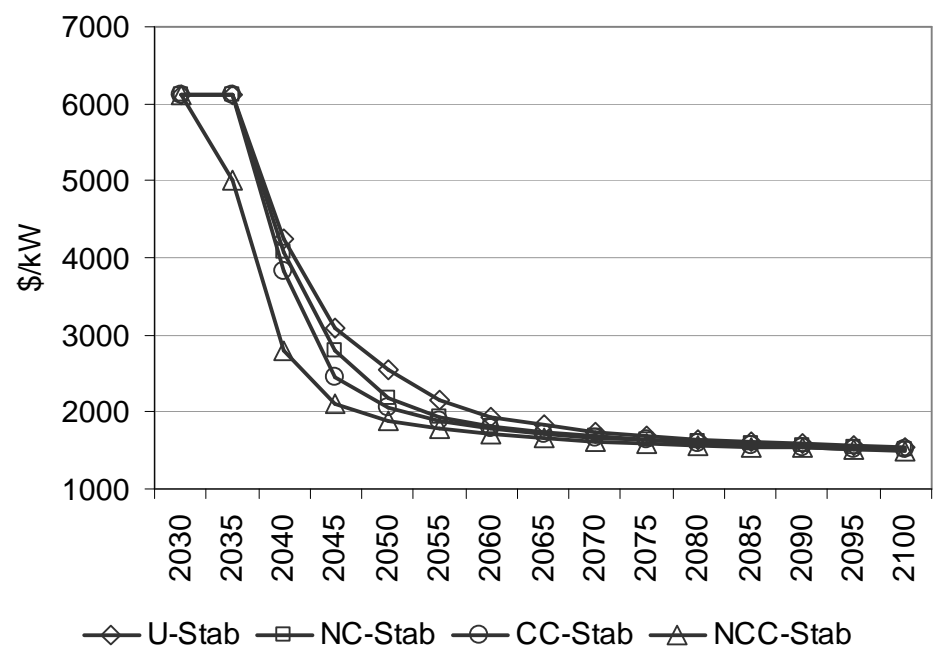

Figure 5. CSP Investment Cost 
Market price for CSP electricity traded

between the EU and MENA

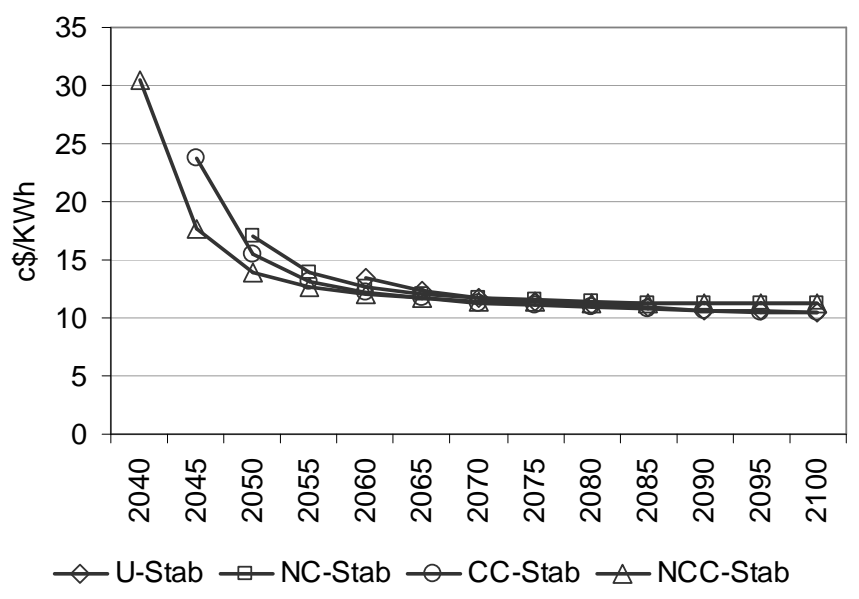

Figure 6. Market Price for CSP Electricity Trade Between the EU and MENA

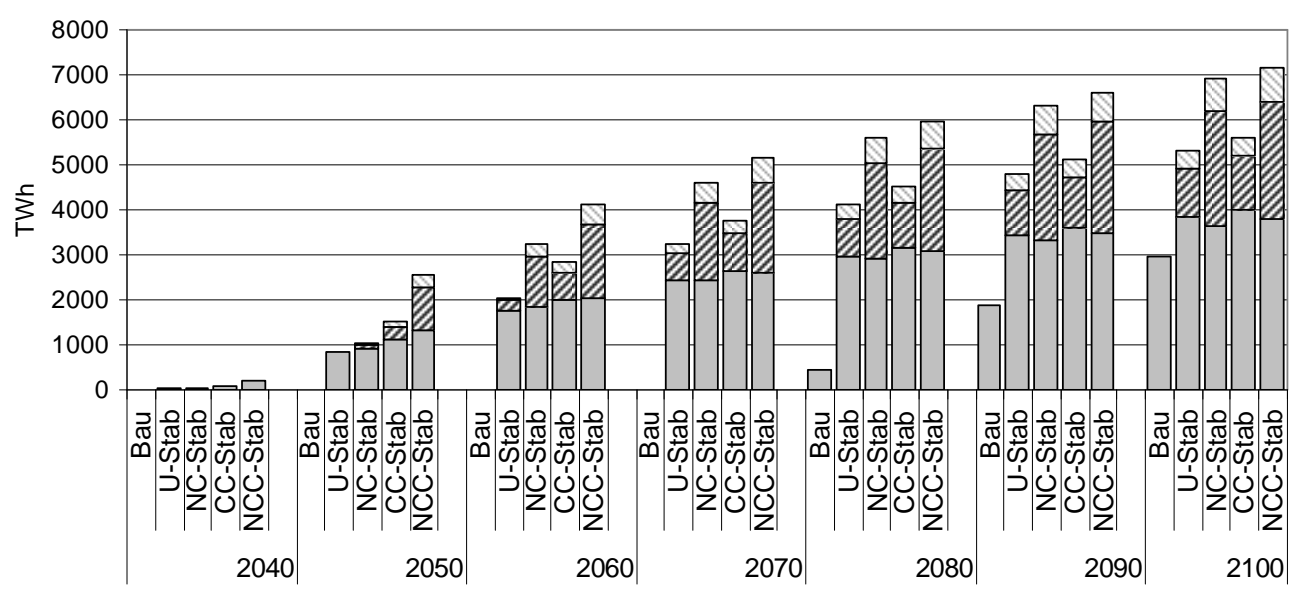

$\square$ MENA domestic use $\square$ Western Europe $\square$ Eastern Europe

Figure 7. Distribution of CSP Power Produced by MENA. 

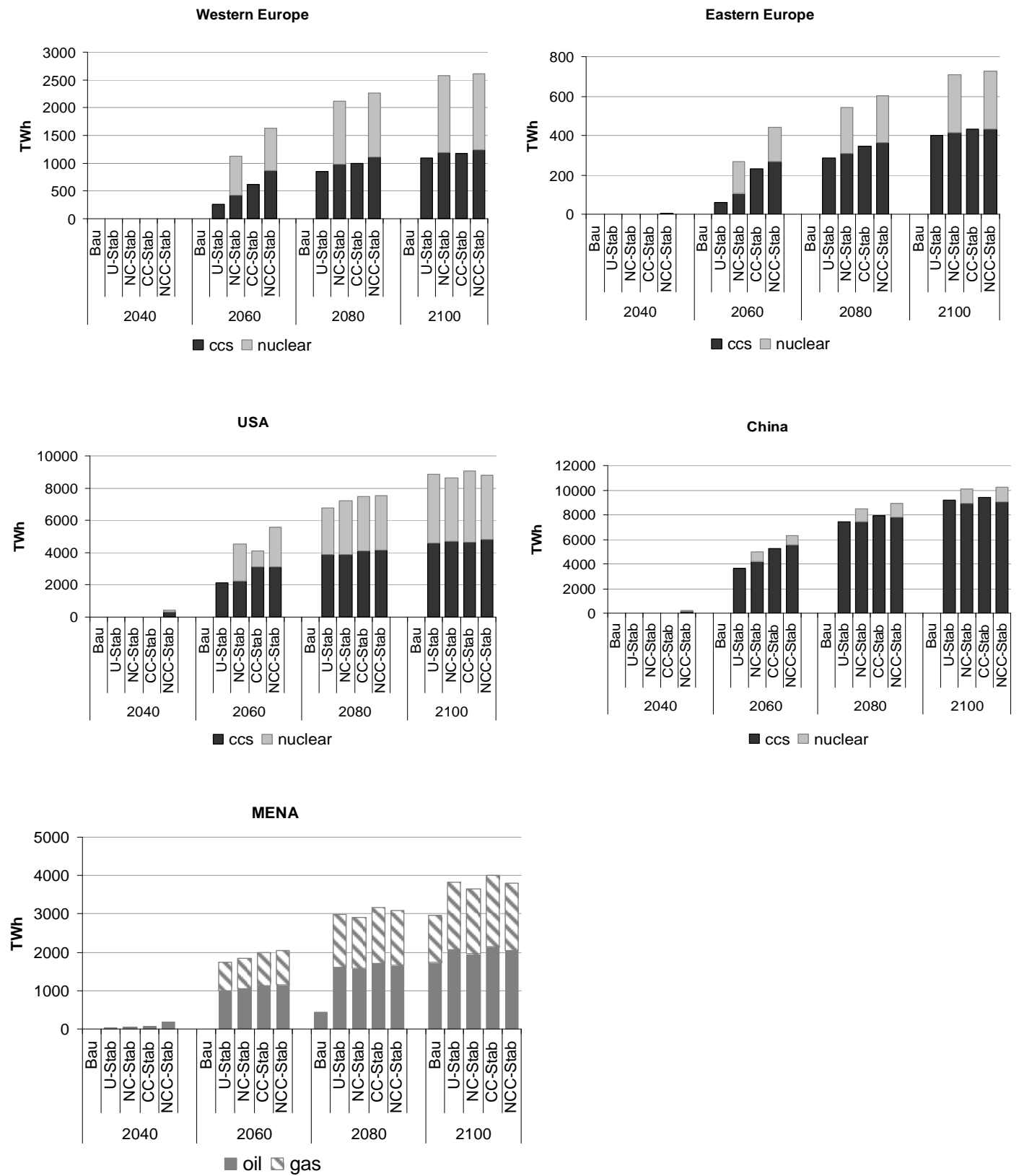

Notes: $\mathrm{Bau}=$ Business as usual; U-Stab = unconstrained stabilization; NC-Stab = constrained stabilization with cap on nuclear; CC$\mathrm{Stab}=$ constrained stabilization with no CCS; NCC-Stab $=$ constrained stabilization with cap on nuclear and no CCS.

\section{Figure 8. Power generation substituted by CSP.}



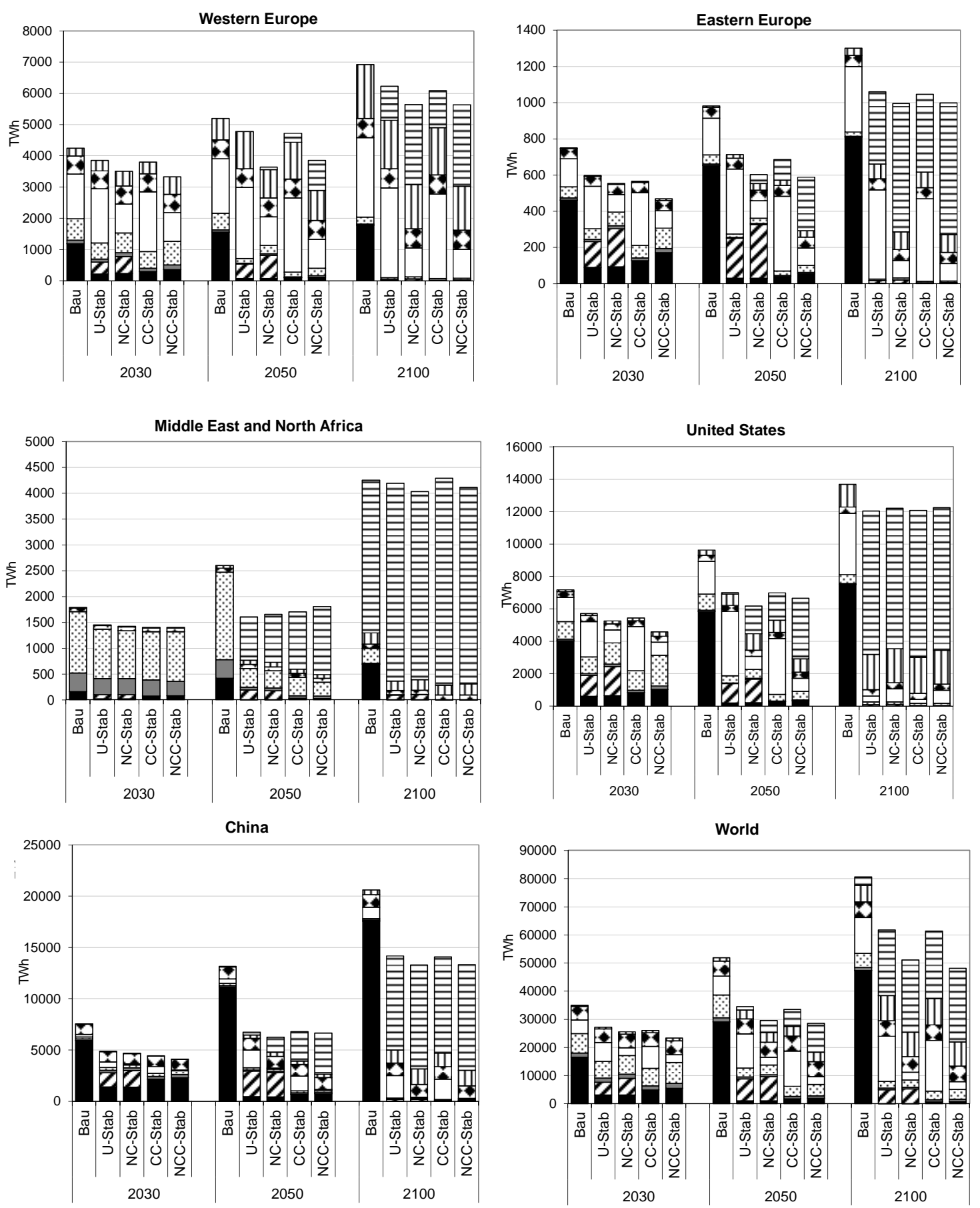

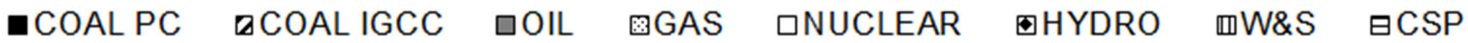

Notes: $\mathrm{Bau}=$ Business as usual; U-Stab $=$ unconstrained stabilization; NC-Stab $=$ constrained stabilization with cap on nuclear; CC$\mathrm{Stab}=$ constrained stabilization with no CCS; NCC-Stab = constrained stabilization with cap on nuclear and no CCS.

\section{Figure 9. Regional and World Electricity Mix}




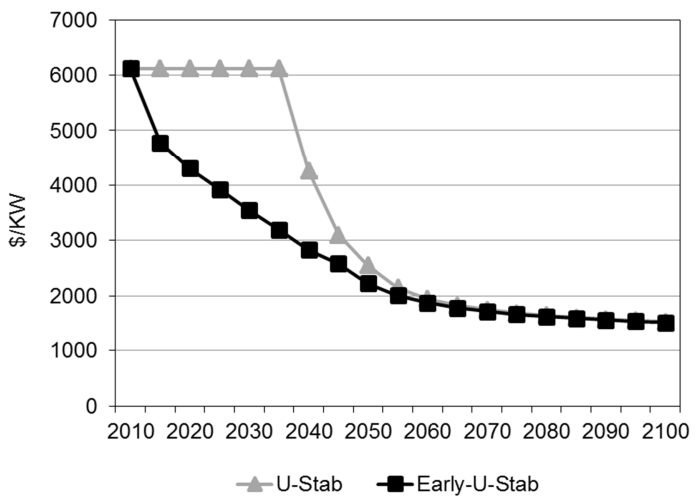

Figure 10. CSP Investments costs for in the unconstrained scenario and in the anticipated investments scenario.
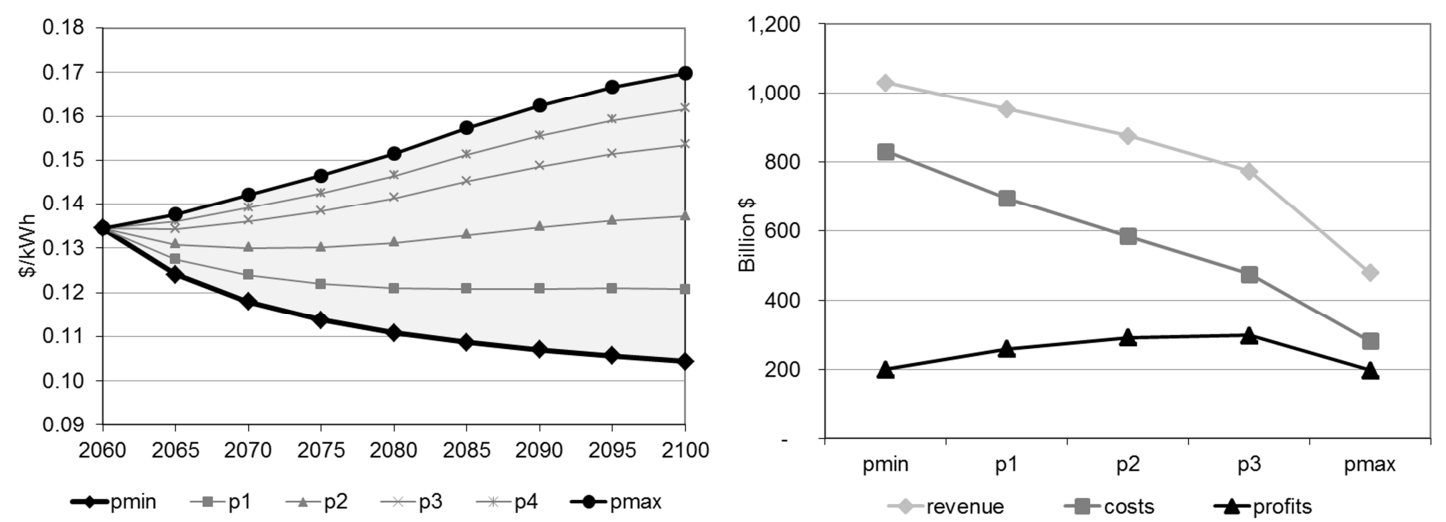

Figure 11. Left panel: price of traded CSP Electricity. Right panel: costs, revenue and profits from CSP electricity trade. 
CSP Investment costs
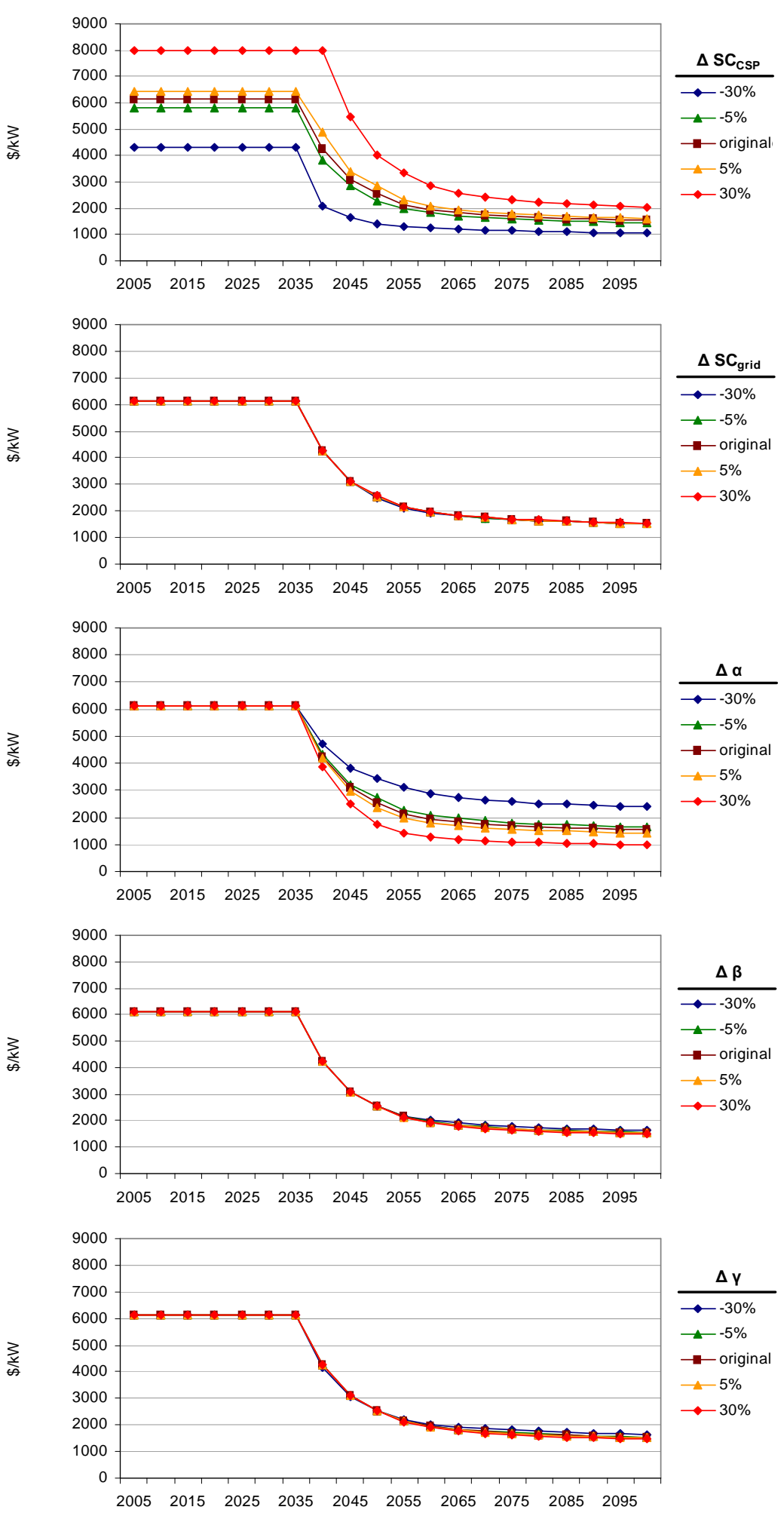

Figure A1. Results of sensitivity analysis on investment cost of CSP capacity. 
EU-Mena trade of SG-CSP Electricity
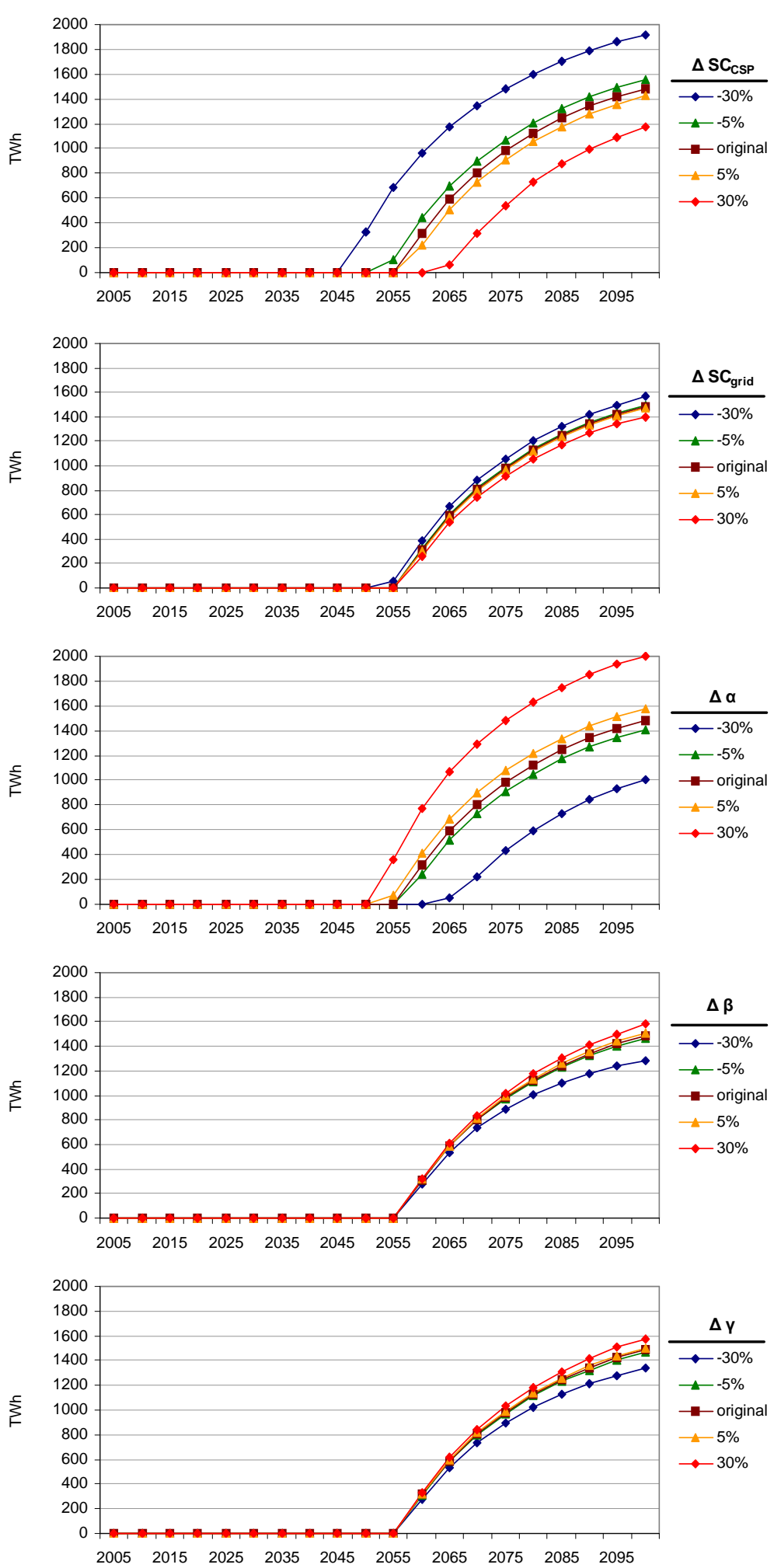

Figure A2. Results of sensitivity analysis on the size and timing of Europe-MENA trade of CSP electricity. 
CSP World Cumulative Installed Capacity

3
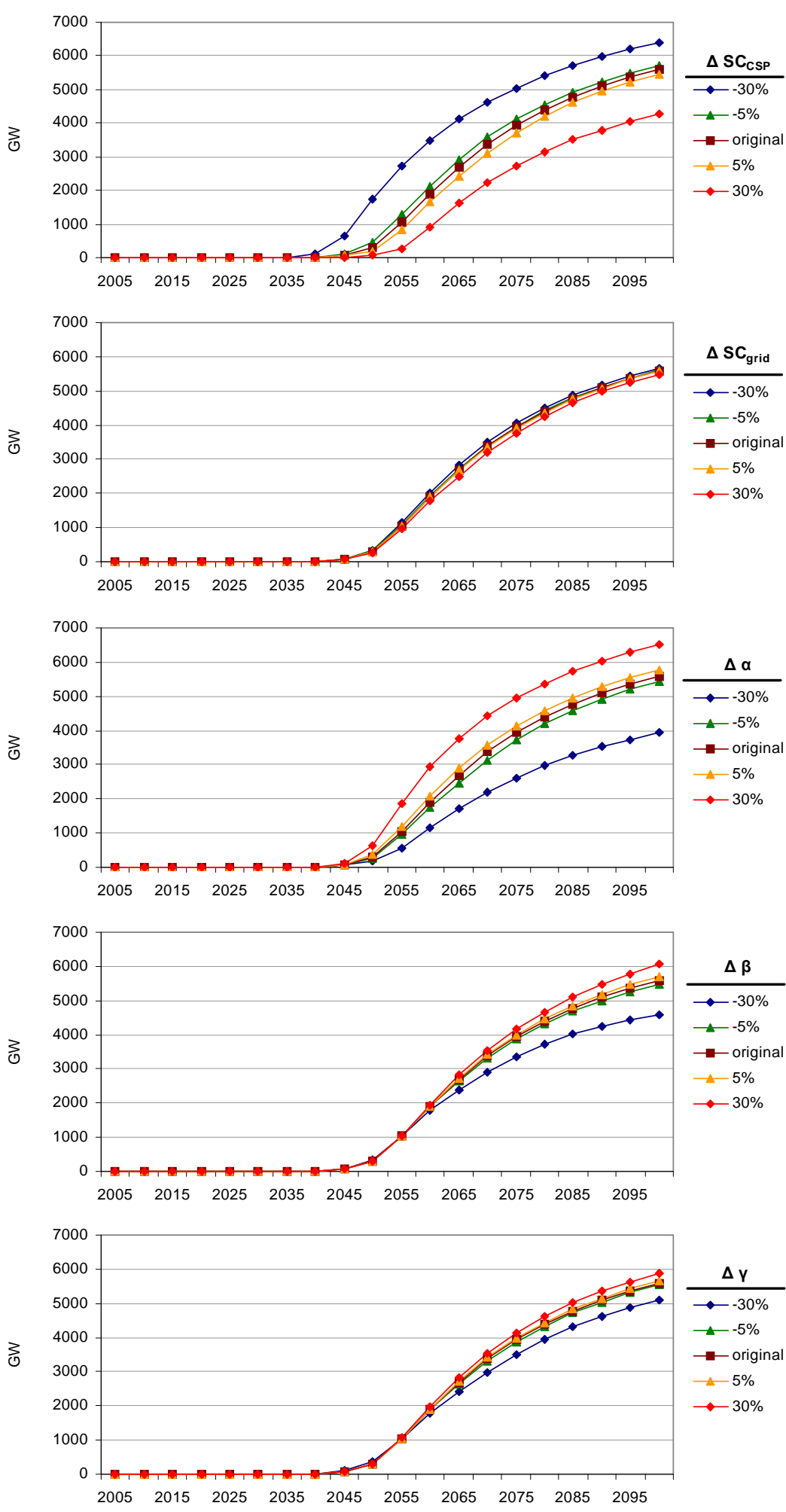

Figure A3. Results of sensitivity analysis on the size and timing of global CSP installed capacity. 